\title{
LOS PECES: UNA UNIDAD DIDÁCTICA EN UNA ESCUELA "DIFERENTE"
}

\section{(Fishes: a didactical unit in an uncommon school)}

\author{
por
}

$\underline{\text { Article record }}$

About authors

$\underline{\text { HTML format }}$

\author{
Aurora Lacueva (1acter@cantv.net) \\ Francisco Imbernón (fimbernon@ub.edu) \\ Rosa Llobera (rllobera@d5.ub.es )
}

Ficha del artículo
Sobre los autores
Formato HTML

\begin{abstract}
In this case study we describe and interpret a didactical experience centered on the theme "Fishes" and developed in a first-grade classroom of an innovative school. We systematically recorded the experience, collected documents, and interviewed the principal, the teacher and the students. Seven categories were used for the interpretation of data: learning connected to the real world, availability of sufficient resources, excessive narrowness of the theme, openness vs. structure in the didactical work, children as protagonists, a rich school life beyond the classroom, and the multi-faceted relation between school and home. The article outlines and discusses children's learning achievements.
\end{abstract}

\section{Keywords}

Educative innovation, science education, democratic education, didactics, elementary school education.

\begin{tabular}{l} 
Resumen \\
En este estudio de casos se describe y se interpreta reflexi- \\
vamente una experiencia didáctica centrada en el tema \\
"Los Peces", y desarrollada en un primer grado de educa- \\
ción primaria dentro de una escuela innovadora. Se llevó \\
un registro sistemático de lo sucedido, se recopilaron do- \\
cumentos y se realizaron entrevistas. Para la interpretación \\
de lo observado, se trabajó con siete categorías que inten- \\
tan destacar importantes características de la experiencia: \\
un aprendizaje vinculado al mundo exterior, disponibilidad \\
de suficientes recursos, la excesiva delimitación del tema \\
en estudio, apertura frente a estructura en el trabajo didácti- \\
co, niños y niñas protagonistas, una escuela de rica vida \\
más allá del aula, y la multifacética relación escuela-hogar. \\
El artículo aporta consideraciones acerca de los aprendiza- \\
jes logrados por los estudiantes \\
Innovación educativa, enseñanza de las ciencias naturales, \\
educación democrática, didáctica, educación primaria. \\
\hline
\end{tabular}

avanzadas de labor. Adicionalmente, intentamos hacer patente a lo largo del estudio la relevancia del contexto escolar en el cual se desarrolla esta iniciativa didáctica específica. Creemos que destacar prácticas pedagógicas positivas y reflexionar sobre ellas puede contribuir al mejor conocimiento del aprendizaje escolar y de los procesos y situaciones que lo 
favorecen, a la vez que aporta orientaciones de interés a docentes y formadores de docentes para su trabajo diario. Consideramos que esta línea de investigación puede acompañar y/o preceder al desarrollo de iniciativas más ambiciosas de trabajo conjunto con maestros y maestras, bajo pautas de investigaciónacción compleja (Carr y Kemmis, 1988; Lacueva, 2000b; Koch y Burghardt, 2002).

Quizás muchas otras escuelas realicen de manera ocasional actividades similares a las que se cumplen en escuelas "alternativas" como ésta, mas se trata de iniciativas aisladas y efectivamente esporádicas. Incluso, ciertos rasgos de la escuela y el aula aquí presentadas pueden ser hoy bastante comunes, al menos en países ricos. Pero lo realmente trascendente es, como en este caso, la conjunción y la sinergia entre características de diversas facetas, y el esfuerzo sistemático desarrollado en varios frentes a la vez, día tras día, mes tras mes, año tras año.

\section{Metodología}

Nuestro trabajo es un estudio de casos, en la línea de lo que Stenhouse (1991) denomina estudio educativo de casos: investigaciones cuyo propósito es mejorar la práctica educativa, y las cuales se orientan hacia el desarrollo de la teoría y/o el refinamiento de la prudencia (entendida aristotelianamente), mediante la documentación sistemática y reflexiva de la experiencia.

Este caso, junto a otros dos no presentados aquí, fue escogido luego de consultas con doce expertos educacionales, visitas a doce escuelas, participación en dos seminarios donde se presentaban experiencias de aula y revisión de tres publicaciones pedagógicas (dos regionales y una nacional).

Observamos a la educadora desde el principio al fin de la unidad didáctica. Llevamos un cuaderno de campo, recogimos trabajos estudiantiles y materiales didácticos repartidos, grabamos en vídeo una clase y en audio otra, tomamos fotografías y esbozamos el plano del aula. También, entrevistamos de manera semi-estructurada a la educadora tanto al principio como al final de la experiencia, y entrevistamos a tres parejas de alumnos al final. Junto a ello, mantuvimos varias conversaciones con la docente, más informales, tres de ellas prolongadas, de más de treinta minutos de duración. La maestra accedió gentilmente a llevar un diario semanal de su labor, utilizando un formato que le suministramos. Realizamos también dos conversaciones con el director de la escuela, una de las cuales con participación de la jefa de estudios, para obtener información general sobre el centro.

\section{Cuadro 1. Procedimientos para la obtención de información.}

1. Notas de campo de la investigadora (de cada clase y otras adicionales de visitas previas o reuniones extras con la docente).

2. Cuaderno de campo con ampliación de notas in situ y añadido de primeras interpretaciones.

3. Transcripción de todo lo escrito en la pizarra.

4. Recopilación de todo material repartido por la docente.

5. Compilación de fotocopias de trabajos de los estudiantes.

6. Recopilación de otros materiales ofrecidos por la escuela (Proyecto de Centro, revistas estudiantiles, revista de la Comunidad Educativa...).

7. Anotación de contenido de carteleras y exhibiciones tanto dentro como fuera del aula.

8. Elaboración de plano esquemático del salón de clases.

9. Realización de fotografías de exterior e interior del plantel, aula, y niños trabajando en esta última.

10. Grabación en audio de una sesión de clase.

11. Filmación en vídeo de una sesión de clase.

12. Utilización de guía estructurada para la recolección de información básica sobre escuela, aula, docente y alumnos.

13. Entrevistas semi-estructuradas a la docente (inicial y final).

14. Entrevistas semi-estructuradas a tres parejas de niños (al final del proyecto).

15. Conversaciones informales con docente observada (registradas en el diario de campo).

16. Diario del docente (semanal).

17. Dos conversaciones con el director de la escuela (en una de ellas participó la jefa de estudios) 
Cuadro 2. Documentos de base utilizados en la interpretación.

19 registros en Cuaderno de Campo y Notas Adicionales

9 materiales repartidos por la docente en clase

59 trabajos de alumnos

1 transcripción de mapa de conceptos hecho en clase

1 vaciado inicial y final de respuestas a inventario de conocimientos. Realizado por la docente

1 vaciado inicial y final de partes del pez señaladas en dibujos. Realizado por la docente

1 guía estructurada de datos básicos de escuela, aula, docente y niños

1 plano del aula

1 transcripción de entrevista inicial a docente

1 transcripción de entrevista final a docente

2 notas de conversaciones informales con la docente (otras están incluidas en Cuaderno de Campo del día correspondiente)

2 notas de conversaciones informales con directivos

3 transcripciones de entrevistas a alumnos

4 diarios semanales de la docente

1 planificación de la Unidad Didáctica

1 comentario de clases observadas dirigido a la docente (a petición)

1 libro artesanal a partir de escritos de los niños, con motivo del día de Sant Jordi (Día del Libro): "Rodolins" ("Pareados")

2 números recientes de la revista de los alumnos

1 publicación con textos de los ganadores de los Juegos Florales del año en la escuela

2 números recientes del Boletín Informativo para los padres

1 número (el más reciente para el momento) de la revista de padres y docentes

1 Proyecto de Centro

(Las transcripciones de las grabaciones en audio y video están integradas a los registros en Cuaderno de Campo)

Luego de transcribir y codificar toda la información, la organizamos e interpretamos de dos maneras: primero, utilizando la narrativa estructuramos una visión unitaria resumida de la experiencia observada, lo que nos permitió una apreciación general articulada del proceso desarrollado; razones de espacio nos obligan a incluir aquí sólo un esquema de la misma. Empleamos también categorías amplias, presentadas como grandes temas, $y$ generadas a partir del estudio de los datos recogidos teniendo como base nuestras concepciones teóricas. La interacción teoríainterpretación de datos llevó de manera dinámica y recursiva a la delimitación de las categorías usadas: destacaron como los rasgos más importantes observados, desde nuestra perspectiva. A continuación, para cada una de tales categorías, se marcó y recopiló toda la información disponible en los datos recogidos.

En esta búsqueda sistemática de la información relacionada con cada categoría y con diversos aspectos dentro de esa categoría, hemos prestado atención no sólo a posibles evidencias confirmatorias de nuestras interpretaciones, sino que también revisamos cuidadosamente por si hubiera evidencias desconfirmatorias. También, hemos tratado de atender no sólo a lo más frecuente y "típico", sino también a lo poco frecuente o atípico. No olvidamos que en un estudio como el nuestro la interpretación y los juicios críticos están presentes desde los inicios y funcionan ya a todo lo largo de la recogida de información. Sólo que, luego de concluida la etapa de campo, el trabajo interpretativo y evaluativo se hace más intenso y sistemático, y se expresa por escrito de manera más exhaustiva.

Podemos delimitar tres tipos de texto en nuestra investigación: descripciones particulares, descripciones generales y los asertos y comentarios orientativos (Erickson, 1998), los cuales se entrelazan intentando llegar a ideas-fuerza orientadoras del trabajo pedagógico.

No podemos contar con todos sus pormenores cada una de las horas de observación 
que vivimos en las aulas: necesitamos realizar estas generalizaciones internas que son las descripciones generales, que elaboramos a partir del estudio de la información recogida. La relativa frecuencia con que se presenta una situación es un dato que puede resultar clarificatorio. En lo posible, hemos cuantificado alguna información de este tipo en nuestro estudio.

También en nuestra exposición nos hemos detenido en ciertos ejemplos, presentados en detalle y de la manera más vívida posible: éstas serían las descripciones particulares. Ellas ofrecen evidencia directa que sostiene nuestras descripciones generales y nuestras interpretaciones, adicionalmente aportan claridad y frescura al informe de investigación. En las mismas incorporamos con frecuencia citas textuales tomadas de los diarios de investigadora y docentes, de los trabajos de los niños y de las entrevistas a niños y docentes. Ello aumenta la autenticidad, interés y comprensibilidad de lo descrito. Por otra parte, de esta manera ofrecemos la oportunidad a los lectores de reflexionar por su cuenta acerca de estas selecciones de nuestra información.

Los asertos y los comentarios orientativos son todas las interpretaciones y reflexiones valorativas del investigador, desde las más específicas vinculadas a determinadas descripciones particulares, hasta las consideraciones teóricas de mayor abstracción. En este grupo de comentarios estarían incluidos también en nuestro caso las reflexiones y propuestas para la acción pedagógica futura. En los asertos y comentarios la interpretación se hace explícita y se presenta fundamentada en la teoría. En ellos se restringe la carga connotativa de los anteriores géneros. Hemos tratado de combinar en nuestro informe estos distintos tipos de texto, de manera que se refuercen e iluminen unos con otros.
Como bien señala Stake (1998), a menudo no aparece con claridad el proceso lógico seguido para llegar a los asertos, las interpretaciones y valoraciones de la investigación. Un estudio de este tipo no es una mera decripción de lo observado, sino que basándose en ella va más allá: hacia la interpretación, la evaluación y, en nuestro caso, la elaboración de "enseñanzas" y mejores pautas de futura acción. El avance interpretativo se basa en nuestras concepciones teóricas previamente estructuradas y también en aquéllas nuevas que construyamos o reforcemos durante la investigación y movidos por ella. También nos ayudan en la interpretación nuestros conocimientos prácticos, y lo que hemos aprendido de investigadores que han realizado trabajos similares.

Siguiendo a Eisner (1998), diríamos que la interpretación trata de explicar (o, quizás, explorar) el significado de las situaciones descritas, mientras que la evaluación añade un juicio valorativo sobre las mismas, en especial en cuanto a su impacto educativo. Las fronteras entre descripción, interpretación y evaluación no son totalmente nítidas, pero la diferenciación de estas tres dimensiones de una investigación cualitativa resulta útil.

Luego del análisis interpretativo y evaluativo de los datos, dedicamos una sección a considerar la información disponible acerca de los posibles aprendizajes de los estudiantes en la unidad didáctica observada. Analizamos evidencias de distintas fuentes y de diferente naturaleza, tratando de clarificar este siempre difícil y complejo interrogante. Finalmente, establecemos conclusiones y señalamos propuestas de trabajo hacia el futuro. 
Cuadro 3. Categorías utilizadas en la interpretación de los datos.

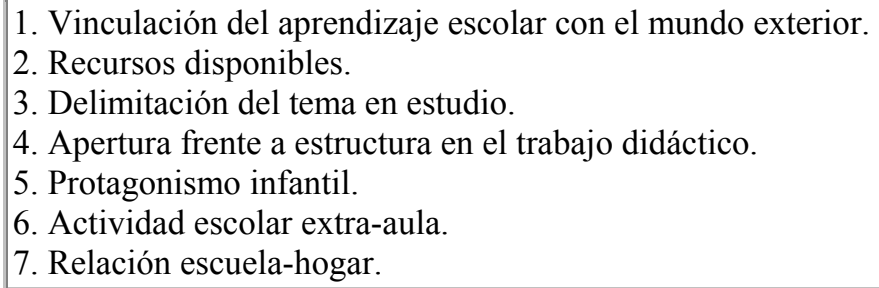

Intentamos asegurar los criterios de rigor de la investigación siguiendo estas pautas (Guba, 1983): trabajo prolongado en el mismo lugar, observación persistente, triangulación (de fuentes, métodos y perspectivas teóricas), recopilación y uso de material referencial, y corroboración estructural.

Se observaron un total de 22,5 horas de clase durante 14 días de 4 semanas efectivas de labor, pues hubo una semana de interrupción por enfermedad de la maestra. Las clases se llevaron a cabo en catalán, con ocasionales acotaciones en castellano, por lo que para este artículo hemos traducido las citas directas presentadas. Los nombres de la escuela, la maestra, otros docentes y los estudiantes han sido cambiados para asegurar la confidencialidad. El trabajo se desarrolló entre febrero y marzo de 1999.

\section{Información de base}

La escuela estudiada se encuentra en una urbanización de nivel socio-económico medio y medio-bajo, ubicada hacia el norte de la ciudad de Barcelona, en Cataluña, España. Pertenece a la red pública, pero tiene una historia peculiar: surgió en los años sesenta del siglo pasado, como una cooperativa de padres y maestros inquietos, que deseaban para los niños una educación más democrática, más rica culturalmente y más vinculada a las raíces catalanas. Con el advenimiento de la democracia en el país, el plantel, junto con otros similares con los que formaba una coalición, pidió ser incorporado a la red oficial, puesto que sus fundadores eran defensores de la escuela pública de calidad.
La institución ofrece los tres niveles de la Educación Inicial o Infantil y los seis grados de la Educación Primaria, una sola sección de cada uno. El nombre de la escuela fue elegido por los estudiantes en sus primeros años y corresponde a un personaje de un libro para niños, en este artículo la denominaremos "Los Tres Osos".

El local escolar es una construcción ad-hoc de tres pisos, con aulas amplias y luminosas, $\mathrm{y}$ ambientes adecuados para actividades especiales: laboratorio, biblioteca, sala de informática, sala de música, laboratorio de idiomas, centro de recursos audiovisuales, ludoteca, gimnasio, cancha de deportes, comedor, taller de artes plásticas, aula de educación especial (hay integración, se usa para trabajos complementarios con docentes especialistas), gabinete del psicólogo escolar (quien viene algunos días cada semana). Hay dos patios, uno de ellos muy grande, con arbustos, árboles, plantas ornamentales, grama, que conforman un espacio grato para el esparcimiento infantil y donde los niños y niñas corren y juegan a sus anchas. El patio más pequeño tiene un parque infantil que usan sobre todo los alumnos de Educación Infantil. La escuela linda con un Parque Natural. Existe también una amplia terraza techada.

El aula de Primer Grado es muy grande y alegre, con dibujos y letreros en las paredes y estantes con libros y materiales, incluyendo un radio-reproductor. Está amueblada con mesas y sillitas, que se disponen de diversas formas según la actividad. 
La maestra observada, a quien llamaremos Marta Montblanc, tenía para el momento de la observación 31 años de servicio, 26 de ellos en esta escuela (no todos en este mismo local). Siempre ha trabajado de manera reconocida como "innovadora". Su formación inicial es de docente con título de nivel medio, posteriormente cursó estudios por libre escolaridad para un título de Magisterio, que en España es una carrera corta a nivel superior. Ha asistido como oyente a varios congresos pedagógicos y ha sido ponente en algunas pocas ocasiones, también ha dictado cursillos en escuelas de verano para maestros. Tiene en su haber dos publicaciones didácticas. En la escuela está considerada como uno de los miembros fundamentales, por sus conocimientos y su experiencia.

Observamos a un grupo de Primer Grado, conformado por 17 alumnos, 9 niños y 8 niñas, todos entre 6 y 7 años de edad. Todos los alumnos habían cursado Educación Infantil. Según la maestra, estaban acostumbrados a la presencia de adultos extraños en el salón, fundamentalmente practicantes $\mathrm{y}$ tesistas de las universidades de la ciudad.

Había dos niñas de origen latinoamericano, los demás alumnos eran de familias españolas, abundaba que uno o dos padres fueran castellano-hablantes. Casi todos eran hijos de empleados medios, aunque había algunos de padres profesionales, y otros hijos de trabajadores manuales.

\section{El desarrollo de la unidad didáctica}

La unidad didáctica Los Peces es parte habitual de la programación para Primer Grado en esta escuela. La profesora Marta explica que ellos cuentan de entrada con el programa Oficial de la Comunidad de Cataluña, pero se apoyan también en los programas de otras regiones de España, concretamente, en este caso han utilizado el de la Comunidad de Madrid, el cual tiene orientaciones precisas de utilidad. A partir de ellos se elabora el Proyecto Curricular de Centro. En la planificación diaria, siguen también de manera parcial el programa Ciencias 6-12, desarrollado por la administración de la Generalitat de Catalunya, y el cual es una adaptación del proyecto estadounidense SCIIS (segunda generación de SCIS).

En la figura 1 presentamos un esquema del flujo de la Unidad Didáctica. Puede apreciarse que las actividades realizadas fueron numerosas y diversas. Hay variaciones en cuanto a lugar de desarrollo, número de participantes, grado de estructuración, tiempo de duración, riqueza de componentes, complejidad de sus exigencias, entre otros factores. Posteriormente reflexionaremos de manera más detenida sobre su calidad. 
Cuadro 4. El flujo de la Unidad Didáctica Los Peces.

\begin{tabular}{|c|c|c|}
\hline \multicolumn{3}{|c|}{$\begin{array}{c}\text { Inicio, Parte I: Exploración de Conocimientos - Inventario y Dibujos } \\
\text { (23 de Febrero) }\end{array}$} \\
\hline \multicolumn{3}{|c|}{$\begin{aligned} \text { Inicio, Parte II: “¿Qué nos gustaría saber de los peces?” } & \\
& (24 \text { y } 25 \text { de Febrero) }\end{aligned}$} \\
\hline $\begin{array}{c}\text { Observar libros } \\
\text { (26 de Febrero) } \\
\text { (9 de Marzo) } \\
(15 \text { de Marzo) } \\
(18 \text { de Marzo) } \\
\text { (22 de Marzo) } \\
\text { Peces de papel, peces de arcilla } \\
\text { (2 de Marzo) } \\
\text { (9 de Marzo) } \\
\text { Recursos de los niños } \\
\text { (10 de Marzo en adelante) } \\
\text { El uso del diccionario } \\
\text { (10 de Marzo) } \\
\text { Escuchar cuentos de peces } \\
\text { (12 de Marzo) } \\
\text { (17 de Marzo) } \\
\text { (22 de Marzo) } \\
\text { Cantar una canción de peces } \\
\text { (17 de Marzo) }\end{array}$ & $\begin{array}{c}\text { La pecera } \\
\text { Montar la pecera } \\
\text { (25 de Febrero) } \\
\text { Llegan los peces } \\
\text { (9 de Marzo) } \\
\text { Observar la pecera } \\
\text { (9 de Marzo en adelante) } \\
\text { La visita al acuario } \\
\text { Preparando la visita } \\
\text { (10 de Marzo) } \\
\text { Cuáles son peces? } \\
\text { (11 de Marzo) } \\
\text { La visita } \\
\text { (11 de Marzo) } \\
\text { Recopilaciones orales y escritas } \\
\text { (11 y } 12 \text { de Marzo) } \\
\text { La lámina del pez } \\
\text { (10 de Marzo) } \\
\text { (15 de Marzo) } \\
\text { Describir una sardina } \\
\text { (16 de Marzo) }\end{array}$ & $\begin{array}{c}\text { Dibujar y/o poner nombres en un } \\
\text { dibujo } \\
\text { El pez por fuera, el pez por dentro } \\
\text { (23 de Febrero) } \\
\text { La pecera } \\
\text { (26 de Febrero) } \\
\text { El pez por fuera } \\
\text { (9 de Marzo) } \\
\text { El acuario } \\
\text { (11 de Marzo) } \\
\text { El pez por fuera, más detalle } \\
\text { (12 de Marzo) } \\
\text { El sistema óseo del pez } \\
\text { (15 de Marzo) } \\
\text { La anatomía interna del pez } \\
\text { (15 de Marzo) } \\
\text { El pez protagonista de un cuento } \\
\text { (16 de Marzo) } \\
\text { Algún momento de otro cuento de } \\
\text { peces } \\
\text { (17 de Marzo) } \\
\text { Una pescadería y sus productos } \\
\text { (19 de Marzo) } \\
\text { El pez por fuera, el pez por dentro } \\
\text { (22 de Marzo) }\end{array}$ \\
\hline $\begin{array}{c}\text { Clasificar } \\
(17 \text { de Marzo) }\end{array}$ & $\begin{array}{c}\text { Observar y registrar comparacio- } \\
\text { nes } \\
\text { (16 de Marzo) } \\
(17 \text { de Marzo) } \\
\text { Disección de peces } \\
\text { (18 de Marzo) } \\
\text { Visita a dos pescaderías } \\
\text { (19 de Marzo) }\end{array}$ & $\begin{array}{c}\text { Escribir nombres } \\
\text { Nombres de peces } \\
\text { (23 de Febrero) } \\
\text { Nombres de peces y no peces } \\
\text { (11 de Marzo) } \\
\text { Nombres de peces y no peces } \\
\text { (19 de Marzo) }\end{array}$ \\
\hline $\begin{array}{l}\text { Video sobre peces } \\
\text { (Después del } 22 \text { de Marzo) }\end{array}$ & $\begin{array}{c}\text { Repaso de preguntas sobre “¿Qué } \\
\text { queremos saber de los peces?” } \\
\text { (22 de Marzo) } \\
\text { Inventario final de aprendizajes } \\
\text { (22 de Marzo) } \\
\text { Lectura grupal de un texto infor- } \\
\text { mativo } \\
\text { (22 de Marzo) } \\
\text { Mapa de conceptos } \\
\text { (22 de Marzo) }\end{array}$ & $\begin{array}{l}\text { Completar frases sobre característi- } \\
\text { cas de los peces } \\
\text { (22 de Marzo) }\end{array}$ \\
\hline
\end{tabular}




\section{Análisis interpretativo del trabajo pedagógico}

El estudio y la reflexión sobre los datos, a partir de nuestras concepciones teóricas, nos ha permitido organizarlos utilizando siete grandes categorías, ellas ayudan a profundizar en algunos de los aspectos claves del trabajo pedagógico. Desde luego, como en toda investigación de este tipo, es mucho lo que dejamos fuera: la vida del aula es de una gran complejidad.

\subsection{Un aprendizaje vinculado al mundo exterior}

Esta escuela hace un esfuerzo sistemático por abrir sus puertas hacia el mundo más allá de sus cuatro paredes, ofreciendo a los niños $\mathrm{y}$ niñas un aprendizaje alejado de los formalismos, la artificiosidad, los rituales vacíos e incluso las banalizaciones de mucha educación "tradicional" (Ramos, 1999). Las unidades didácticas, según lo observado y conversado, implican siempre el conocimiento directo de otros ambientes y otras personas, y/o la creación en el aula y plantel de miniambientes que reproducen algo de la vida externa. La observación, las comparaciones, la escucha de explicaciones, el planteo de preguntas, están presentes en estos contactos con el mundo de afuera. Así, según nos informa la docente, en una unidad didáctica previa a "Los Peces" los estudiantes visitaron una granja; luego, en la unidad didáctica de "La Casa", oyeron las explicaciones y observaron los instrumentos de dos padres: un albañil y un electricista; y al estudiar las estrellas asistieron al planetario. En "Los Peces", como hemos reseñado, visitaron un acuario y dos pescaderías. Además de ello, montaron la pecera en el salón de clases y observaron la disección de varios peces.

Estos contactos proveen vivencias ricas y diversas, que aumentan los conocimientos infantiles y facilitan el aprendizaje escolar. Estudios muestran que en el aprendizaje de conceptos biológicos, por ejemplo, los niños que poseen mascotas o que cuidan animalitos en clase poseen una rica base de conocimientos, que les permite usar sus nuevos saberes científicos de manera más flexible, realizar analogías y predicciones más plausibles y generalizar más que los niños que tienen el mismo conocimiento formal pero carecen de la experiencia práctica (Hatano e Inagaki, 1997).

Por el resto del año, la pecera o acuario permaneció en el aula. Los niños y niñas la observaban con frecuencia al entrar o salir de clase y en los recesos. La maestra puso lupas al lado para observar. Diversas novedades llamaron la atención de los pequeños y generaron preguntas e inquietudes. La profesora Marta realizó varias explicaciones e intercambios con los alumnos en torno al acuario: cómo hay que usar el termostato, cómo se elabora la comida para peces, para qué sirve el recipiente pequeño que se llama "paridera", etcétera. Incluso, en una oportunidad apareció un pececito muerto y la maestra discutió con los niños y niñas hipótesis sobre este suceso, en un intercambio muy fluido de ideas diversas. También usó este microambiente para una actividad de evaluación hacia el final del trabajo.

(Síntesis de notas de campo, varias sesiones).

La variedad de ambientes y experiencias reales tiene también una carga afectiva notable: a menudo, consigue llamar la atención e interesar, por su autenticidad, novedad y complejidad.

Entramos al aula. Los niños cuelgan sus chaquetas de los ganchos apropiados.

De pronto unos anuncian:

- ¡Ha parido la hembra!... iY hay pequeños!

Aglomeración, entusiasmo, revuelo. Todos van hacia la pecera. 
Rápidamente, la maestra manda a hacer una fila, el que se queda de último llora.

(Diario de campo, 10-03).

El intercambio con guías y otro personal de los ambientes visitados fuera del aula permite aprender de expertos diversos, no dependiendo sólo de los conocimientos y perspectivas del docente. Los expertos externos poseen saberes, experiencias y puntos de vista que el educador o educadora no puede poseer, y enriquecen de este modo el aprendizaje infantil.

Hay gran animación de los niños al llegar al acuario, se agolpan alrededor de los diversos tanques y comentan unos con otros lo que ven. Luego, van siguiendo las explicaciones del guía, que son sencillas y amenas, acordes a la edad de los estu- diantes. Al final el guía alimenta a los peces, lo que genera más acción, interesante de observar. Los niños tienen oportunidad de plantear sus preguntas: ¿el caballito de mar es un pez?, ¿los peces tienen lengua?, ¿los peces duermen?

El guía nos muestra también una mandíbula de tiburón grande y el caparazón de una langosta.

\section{-Está muerta - dice una niña.}

-No, no está muerta. -explica el guíaConforme las langostas van creciendo, cambian de caparazón como si cambiaran de camisa. Cuando se les queda pequeño, salen de él y se refugian en las rocas, hasta que su cuerpo blando genera otro caparazón más grande. Es como su armadura.

(Diario de campo, 11-03).

Cuadro 5. Aprendizaje vinculado al mundo exterior.

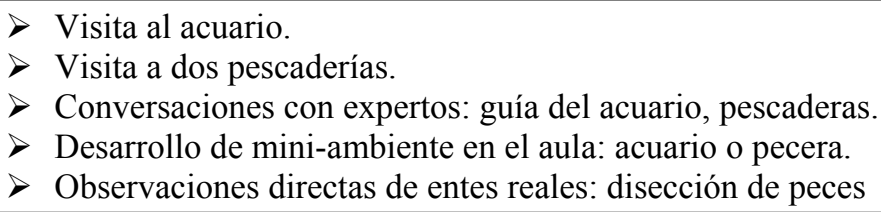

\subsection{Disponibilidad de suficientes recur- sos}

El equipo docente de "Los Tres Osos", y en particular la profesora Marta, se preocupan por poner al alcance de los niños una variedad de recursos útiles para su aprendizaje. Para ello cuentan con el apoyo financiero del gobierno de su comunidad regional, el cual tiene a su cargo la educación. En primer lugar, destacan los numerosos libros que los estudiantes manejaron en el transcurso de la unidad didáctica: libros informativos de bellas y llamativas ilustraciones, algunos para estudiantes más avanzados pero de los cuales la profesora aprovechaba las buenas imágenes y los títulos y subtítulos breves y de letra grande; así mismo libros de cuentos diversos. Los niños y niñas que terminaban antes que otros una actividad podían ir al rincón de biblioteca y ponerse a leer un libro por su cuenta. La profesora Marta era un buen modelo de lectora, varias veces señaló que ciertas informaciones que les estaba dando las había obtenido leyendo tal o cual libro (incluso libros traídos por los niños), también a veces fotocopiaba páginas pertinentes de estos libros y las pasaba entre los pequeños. En ocasiones, al mostrar un libro aprovechaba para señalar la tabla de contenido y para remarcar su utilidad. El diccionario fue usado en clase por Marta, pidiendo ella a los alumnos que la ayudaran a buscar la palabra "pez" y leyendo luego la definición allí presentada. Se trataba, por cierto, de un diccionario ilustrado, especial para niños pequeños. La profesora visita regularmente librerías especializadas en textos educativos, así como 
centros de recursos estadales y adquiere, con un fondo económico del plantel, libros, láminas y otra dotación. De este modo consiguió, por ejemplo, una lámina a colores de la anatomía del pez, que no había usado en años anteriores, y que constituyó un útil aporte para la unidad didáctica.

La pecera, desde luego, fue otro importante recurso utilizado, el cual permitió la observación cercana y directa de peces, caracoles $\mathrm{y}$ algas durante un tiempo prolongado. No somos muy partidarios de estos ambientes artificiales donde se mantienen atrapados seres vivos y sensibles. Pero reconocemos que, usados prudentemente, resultan un valioso apoyo para el aprendizaje infantil.

Además de esto, los niños y niñas tenían a su alcance variedad de dotación para su trabajo: creyones de madera y de cera, marcadores, pintura, cartulina, papel, tijeras punta roma, goma, entre otros implementos. Los ambientes extra-aula del taller de artes plásticas y el laboratorio ofrecían recursos adicionales para el trabajo estudiantil de calidad.

La profesora Marta disponía en el plantel de la posibilidad de hacer fotocopias para usarlas en su trabajo con los alumnos, y de hecho realizó bastantes: hojas con dibujos para poner nombres y otras actividades sencillas y estructuradas de papel y lápiz. Así mismo, la educadora contaba con computa- doras e impresoras, aunque no dentro de la misma aula. En una oportunidad, un grupo de niños fue con el pasante a escribir en computadora un texto colectivo sobre su visita al acuario, el cual fue posteriormente publicado en la revista de la escuela.

Resulta muy interesante la contribución de las familias a la gama de recursos para cada unidad didáctica, la cual es sistemáticamente solicitada por la docente. En "Los Peces" la colaboración fue variada y útil: bellos libros y pertinentes vídeos fueron prestados por los estudiantes y sus padres. Los peces para la disección constituyeron otra colaboración de las familias y, aunque abundaban las sardinas, algunos padres aportaron pescados más grandes y costosos.

La variedad de recursos permite variar las actividades y ofrecer más completas y diversas fuentes de información a los pequeños, junto a un ambiente más estimulante y retador para el trabajo. Los recursos ofrecen herramientas para potenciar la reflexión y la acción infantiles: toda una historia de cultura y civilización y todas unas nuevas posibilidades de hacer y de pensar entran al aula con cada recurso que se incorpora (Alberti, 1977). A la vez, al solicitar a los estudiantes que aporten recursos a la clase, que son luego usados, la escuela les enseña que un buen aprendiz también construye su propio ambiente propicio de trabajo y busca útiles instrumentos de labor (Claxton, 2001).

Cuadro 6. Disponibilidad de recursos.

Libros informativos.

$>$ Libros de cuentos.

$>$ Fotocopias.

> Láminas.

$>$ Vídeos.

$>$ Acuario o Pecera en el aula.

$>$ Creyones de madera y de cera, marcadores, pintura, cartulina, papel, tijeras punta roma, goma de pegar.

$>$ Recursos del laboratorio: cuchillo, tijeras grandes, bandejas, agua corriente.

$>$ Recursos del taller de artes plásticas: arcilla, rodillos, punzones, espátulas, tenedores, tablas.

$>$ Computadoras, impresoras.

$>$ Recursos aportados por las familias: libros, vídeos, peces de juguete, peces para disección 


\subsection{La excesiva delimitación del tema en estudio}

Encontramos que como tema "Los Peces" resulta demasiado limitado para una unidad didáctica de nivel primario. Puede ser un punto de partida, pero no un centro de atención "fuerte", pues no permite suficientes ramificaciones y facetas a este nivel, aun cuando el pez era tomado en la planificación del centro como un ejemplo del tema más amplio "Seres vivos". La profesora Marta nos señaló al principio de la unidad didáctica que los objetivos de la misma eran estudiar qué es un ser vivo, características de un ser vivo y de su ciclo de vida, y qué es un vertebrado, usando como caso el pez; y considerando así las partes más importantes del organismo de este animal y su funcionamiento: cómo respira, cómo nada... También, dónde vive. Otro objetivo de la unidad era ampliar el vocabulario de los niños y niñas, incluyendo el aprendizaje de diversos nombres de peces. Y saber que no todos los animales que viven en el agua son peces. En cuanto a procedimientos, Marta consideraba que hay algunos implicados en el mantenimiento de la pecera y en la disección del pez. Por lo que respecta a las actitudes, la profesora destacó: cuidar los peces de la pecera, no maltratarlos. De una forma más general, la unidad también buscaba incentivar la curiosidad (véase Plan de la Unidad en Anexo).

Estimamos que estos objetivos realmente guiaron el trabajo. Por una parte, ayudaron a que no se perdiera el rumbo y se persiguieran con sistematicidad ciertos logros. Pero, por otra, también focalizaron demasiado la labor para el nivel, y a partir de ellos derivaron algunas actividades muy estructuradas, como poner nombres de órganos en dibujos o responder preguntas de simple conocimiento sobre nombres de peces o partes de un pez, las cuales se repitieron con demasiada insistencia, como puede apreciarse en la figura 1.
Aurora Lacueva (AL): ¿Qué fue lo que menos te gustó (del tema)?

Adriana: Pues... saber, entender... eee, bueno saberme yo las..., muchas... muchas... entender aaa las cosas... (frase corta ininteligible) bueno... No me gustó... era trabajar todo... todo el día el... el... el tema de peces. (...)

\section{AL: ¿Por lo cansado?}

\section{Adriana: Sí, porque todo el día haciendo peces y peces y peces...}

(Entrevista final a alumnos Adriana y Oscar).

Creemos que en el nivel primario y aún en el secundario o medio, deben predominar los temas más amplios, que permitan considerar asuntos más diversos, aunque relacionados entre sí, temas como por ejemplo "La vida en el mar". La multiplicidad de asuntos, las ramificaciones, las vinculaciones, posibilitan mayor diversidad de actividades, permiten captar el interés de más estudiantes durante más tiempo, ofrecen visiones más complejas e integradas, y contribuyen así más al aprendizaje estudiantil.

La centración en los peces llega probablemente a cansar a muchos niños y niñas, especialmente a la hora de las actividades más estructuradas de papel y lápiz y de los excesivos recuentos. Así nos pareció percibirlo durante las observaciones: la atención fue muy alta alrededor de la pecera, las visitas al acuario y las pescaderías y la disección del pez. Fue bastante intensa en las discusiones y sesiones de elaboración de preguntas. Pero oscilaba y en algunos estudiantes francamente cesaba en los ejercicios de papel y lápiz de nombrar o dibujar partes del pez y completar frases.

La preocupación por reafirmar nociones específicas no debe primar en los grados iniciales de la escolaridad, es preferible el tratamiento menos reiterativo de mayor número de saberes, que poco a poco el aprendiz 
irá organizando, reorganizando y consolidando a lo largo de su escolaridad. En el fondo parece dominar en las escuelas, incluso en ocasiones en escuelas como "Los Tres Osos" -comprometidas con una formación más completa y significativa de los estudiantes-, una visión de la mente como un gran rompecabezas, donde gracias a la educación escolar se van incorporando y encajando pequeñas piezas poco a poco, de manera sistemática y firme. Nos inclinamos por las posiciones que, basadas en la investigación empírica y la reflexión crítica, consideran el aprendizaje como algo más fluido y difuso, un proceso dilatado a lo largo del cual las nociones se van consolidando de manera más entrelazada y progresiva, y donde pueden darse amplias reorganizaciones de las "teorías" y "mini-teorías" mentales (Claxton, 1994; Gallas, 1995). Es la visión de una mente no atomística sino gestáltica, cuyos conceptos y teorías o mini-teorías tienen una estructura que trasciende la simple suma de sus partes constituyentes y donde la ecología del pensamiento condiciona cada proceso cognitivo específico; una mente cuyo funcionamiento va más allá de la fría literalidad y la lógica formal para abarcar esfuerzos imaginativos intensos, con el uso de metáforas, metonimias e imágenes mentales, y donde la emoción energiza y orienta a la razón; una mente no abstracta sino enraizada en nuestras características corporales y basada en esquemas preconceptuales producto de nuestra experiencia con el mundo físico y social (Lakoff, 1987; Lakoff y Johnson, 1999; Damasio, 1994). Si bien otras características de la unidad didáctica observada se compaginan bien con esta visión de la mente de los aprendices, tanto la estrechez del ámbito nocional considerado como la ultraestructuración y simplificación de algunas de las actividades (que consideramos a continuación) van en contra de ella.

Cuadro 7. Delimitación del tema en estudio.

\begin{tabular}{|c|}
\hline El pez como ejemplo de ser vivo \\
Conocimientos conceptuales \\
El pez por fuera \\
El pez por dentro \\
Cómo funciona, cómo vive \\
Cómo se reproduce \\
Nombres de algunos peces \\
Peces y otros animales acuáticos \\
Conocimientos procedimentales \\
Mantenimiento de la pecera \\
Disección del pez \\
Conocimientos actitudinales \\
Cuido de peces de la pecera \\
Curiosidad por los animales acuáticos, especialmente los peces \\
\hline
\end{tabular}

\subsection{Apertura frente a estructura en el trabajo didáctico}

Se aprecia una combinación de actividades más y menos hetero-estructuradas a lo largo de la unidad didáctica, también una combinación de actividades amplias y otras más focalizadas. Así, entre las actividades más multifacéticas y abiertas, cargadas de múlti- ples potencialidades de aprendizaje están: el montaje y la observación de la pecera, la disección de peces, la visita al acuario y la visita a las pescaderías. Es cierto que fue la profesora quien montó en sí la pecera y quien abrió los peces, limitándose los niños a observar, pero eran actividades complejas, a partir de las cuales podían lograrse aprendizajes diversos y surgir diversas inquietudes. 
Hubiera sido difícil, aunque quizás no imposible, poner a los niños y niñas a participar más en ellas, y en realidad la profesora les ofreció cierta participación, como su trabajo transportando los materiales de la pecera hasta el laboratorio, su ayuda en el lavado de piedrecillas y en la ubicación de aparatos, y la posibilidad que tuvieron de observar de cerca y tocar los peces diseccionados. Siendo amplias, no eran actividades desorganizadas, pues la profesora Marta cuidó de darles cierta orientación y armazón. Por ejemplo, a partir de las preguntas que ella iba planteando antes, durante y al finalizar la actividad. $\mathrm{O}$ gracias a actividades cortas acompañantes o de cierre, que pedían a los estudiantes evocar ciertas nociones, recordar observaciones, comparar rasgos de seres vivos, clasificar, etc.

Ahora la maestra abre con unas tijeras grandes la caballa. Hay una emocionada expectativa en la clase, mezclada en varios con algo de asco. Algunos se tapan los ojos, entreabriendo luego poco a poco los dedos. Hubo un niño que no quiso ver la disección, la docente no lo forzó a ello. La maestra enseña el pez abierto, luego va extrayendo algunos órganos: corazón, hígado, intestinos... Dice que los intestinos dentro tienen la caca, los abre y los exprime tranquilamente, mientras los estudiantes miran muy atentos y varios dicen ";Uagghh!”. La maestra sigue: musculatura, columna vertebral... - ¿Hay preguntas? -dice Marta. Los niños y niñas levantan la mano: es verdad que las espinas son pequeñas, a mí una vez se me clavaron tres, cuenta Igor; ¿por qué el corazón es tan pequeño?, pregunta otro niño; yo pensaba que la sangre no era negra, dice Adriana, quien observó muy bien la disección por estar al lado de la maestra. La maestra va respondiendo y repreguntando: el corazón, en proporción, no es tan grande, incluso el nuestro; unas pocas gotas de sangre se ven de color rojo (se pone unas en la mano y pregunta el color), cuando hay mucha se ve negra...
Saca los otros peces traídos y sin abrirlos los pasa para que todos los niños los observen y toquen, lo cual hacen con gran interés todos, menos el niño que no quiso mirar, Gilbert B.

Posteriormente, la profesora Marta abre los peces y los vuelve a pasar abiertos, la observación atenta de los pequeños se mantiene. Como ella ha modelizado antes el proceso, saben observar mejor, fijándose en más detalles. Marta se voltea un momento a lavarse las manos y rápidamente una niña toma las tijeras y trata de sacar el ojo de una caballa. Ante el grito de la educadora, la alumna suelta el punzante instrumento. Marta saca el ojo para ella: llama la atención por lo grande y profundo que es, muy esférico. La niña lo toma en su mano y lo examina, mientras otros compañeritos se congregan a su alrededor.

(Síntesis de notas de campo, 18-03).

Por otra parte, existieron actividades muy estructuradas desde afuera, donde lo que los niños y niñas debían hacer estaba bien pautado, es el caso de todas las actividades de papel y lápiz, centradas en dibujar, poner nombres en dibujos o completar frases. Si bien usadas moderadamente permiten focalizar y consolidar aprendizajes, en este caso nos pareció que hubo un exceso de ellas, lo cual está vinculado con el excesivo centramiento en un tema más bien limitado como el de "Los Peces".

De un carácter intermedio en su apertura estuvieron presentes actividades como la observación y registro comparativo siguiendo formato de características de "guppies" macho y hembra y de "guppies" y caracoles acuáticos, la descripción de una sardina, y la elaboración junto a la docente de un mapa de conceptos. 
Complementaron la labor las actividades relacionadas de áreas no científicas, como las de escuchar cuentos de peces, cantar, o hacer peces en papel o arcilla.

Algunas actividades estructuradas demasiado sencillas, basadas en la copia o la memorización, pudieron haberse sustituido con provecho por actividades más complejas. Por ejemplo, en vez de dibujar y poner nombres, construir un modelo tridimensional del interior de un pez, con materiales de desecho como tubitos de goma, palitos, gomaespuma o "foami", globos, poliestireno, cartón, pitillos, papel de seda, plastilina, etc. $\mathrm{O}$ en vez de resumir un cuento, inventarle otro final.

El planteo de inquietudes infantiles al inicio de la unidad ("¿Qué queremos saber de los peces?") constituyó una buena iniciativa, así como el reconocimiento dado a las preguntas formuladas, al escribirlas en folios grandes y pegarlas en las paredes del aula. Estas preguntas tuvieron cierto peso durante el desarrollo de la unidad, si bien sólo parcial. Pero fueron consideradas antes de ir al acuario. $\mathrm{Y}$ al cierre del proceso, se retomaron para ver las respuestas del grupo a ellas, actividad ésta sin embargo que se cumplió de manera algo apresurada, por limitaciones de tiempo. Diríamos que los interrogantes infantiles no fueron el eje del trabajo, pero recibieron consideración. Hubo allí un esfuerzo porque el alumnado participara más en su propia formación y valorara más lo realizado y alcanzado, lo que constituye un estímulo a la metacognición, tan necesaria en un aprendizaje fecundo y duradero (Claxton, 2001; Bransford y otros, 2000).

Resulta interesante notar que la profesora Marta, si bien focalizada en peces, se esforzó por extender muchas actividades, logrando que ellas tocaran otros asuntos aparte de su tema central, enriqueciendo más la formación infantil y ofreciendo seguramente algo de interés a todos o casi todos los estudiantes de su aula. Así, aunque este año debido al pronóstico de lluvia la visita al acuario se hizo en un autobús alquilado al efecto, normalmente Marta, con ayuda de otros profesores y/o pasantes, lleva a los niños en el "metro" y el tren, aprovechando que hay paradas cerca de la escuela y del acuario. Como la profesora explica: "La finalidad es ver el acuario, pero hay también otras cosas nuevas en esta excursión" (Entrevista 1, M. Montblanc).

A menudo, las preguntas de Marta Montblanc sobre una actividad llevaban a temas relacionados que habían sido tocados en ella. Por ejemplo, cantar una canción de peces y pesca, era un momento ameno y de unión en el grupo, que traía a colación además algo visto en la clase de música. Pero Marta aprovechó también para hacer preguntas sobre métodos e implementos de pesca que conocían los niños y niñas, recibiendo buenas respuestas. En ocasiones, esta estrategia podía hacerse un poco forzada, pero habitualmente era interesante y productiva.

El tratamiento prolongado de un tema permite un aprendizaje más variado y sólido, dando tiempo para explotar diversas facetas y para que los niños y niñas vayan reorganizando sus "mini-teorías" sobre el asunto.

Una escuela con tantos rasgos estimuladores del aprendizaje como "Los Tres Osos" y una maestra tan preparada, experimentada y dedicada a su labor como Marta Montblanc, ¿cómo es que no ensayan estrategias didácticas más abiertas y de carácter más fuerte en cuanto a la investigación infantil como, por ejemplo, los proyectos de investigación (Blumenfeld y otros, 1997; Manning, Manning y Long, 2000; Lacueva, 2000a)? En realidad, sí lo han hecho. Pero han terminado decepcionados de ellos. Tanto la profesora Marta como los dos directivos entrevistados consideraban al momento que los proyectos de aula no eran positivos: a menudo, señalaban los docentes, los temas de investigación se repiten de grado a grado, también se abordan temas que interesan a los niños líderes o a los que más intervienen en clase y no al 
común del alumnado, así mismo ha sucedido que con frecuencia los alumnos proponen temas sobre los que ya saben algo, no temas realmente nuevos que desean conocer. "Tampoco funcionó aquello de que todas las conclusiones salieran de los propios niños", agrega Marta. Y completa con convicción: "El maestro tiene que tener claros los objetivos, no se puede trabajar sin objetivos como en los proyectos". (Conversación con M. Montblanc, 27-01). Ella pasa horas planificando actividades con el equipo docente de la escuela y luego preparando los materiales para las mismas.

Estos educadores no ven mayores diferencias entre las actividades cumplidas en un proyecto planteado por los niños y niñas y las que ellos pueden proponer en una unidad didáctica, pensada y organizada "desde afuera". Consideramos que se equivocan en sus conclusiones, y que las mismas derivan de una cierta manera de enfocar los proyectos de aula, la única con la que ellos han tenido relación. Con frecuencia las modas pedagógicas impuestas de manera tajante, de forma apresurada y rígida, mueren al poco tiempo, por no poder adaptarse a las variadas y cambiantes condiciones escolares, por no respetar las complejidades a las que se enfrentan los educadores en esos ambientes, y por no permitir una curva de desarrollo paulatino de la innovación. Así, poderosas propuestas como la investigación infantil a partir de temas de su interés, son desechadas al no haber llegado a implementarse adecuadamente.

Pregunto por influencias pedagógicas y el Director responde que ha ido cambiando. Al principio fue Freinet, luego hubo un tiempo cuando todo era Piaget y la Pedagogía Operatoria, y ahora el Constructivismo.

Aurora Lacueva: ¿Por qué desecharon Freinet? ¿No funcionó o simplemente pasó de moda?

Director: Yo diría que fue por modas. Vino lo de la Pedagogía Operatoria. En aquella época todo se hacía quizás de manera demasiado dogmática, exclusiva, sin introducir cambios o adiciones o mezclas. Por ejemplo, en la Pedagogía Operatoria no podíamos usar textos. Y algunos maestros decían que eso podía funcionar en ciencias, pero que a lo mejor en matemáticas sí era útil tener un texto, pero entonces no se aceptaba. Incluso, un grupo de maestros la cogió tan fuerte que cuando en la escuela se introdujeron cambios en la Pedagogía Operatoria, ellos (...) se fueron. (...) Ahora, con lo del Constructivismo, vemos que algunas cosas que dicen ya las hacíamos, pero de manera intuitiva.

(Entrevista 2 al Director). 
Cuadro 8. Apertura frente a estructura en el trabajo didáctico.

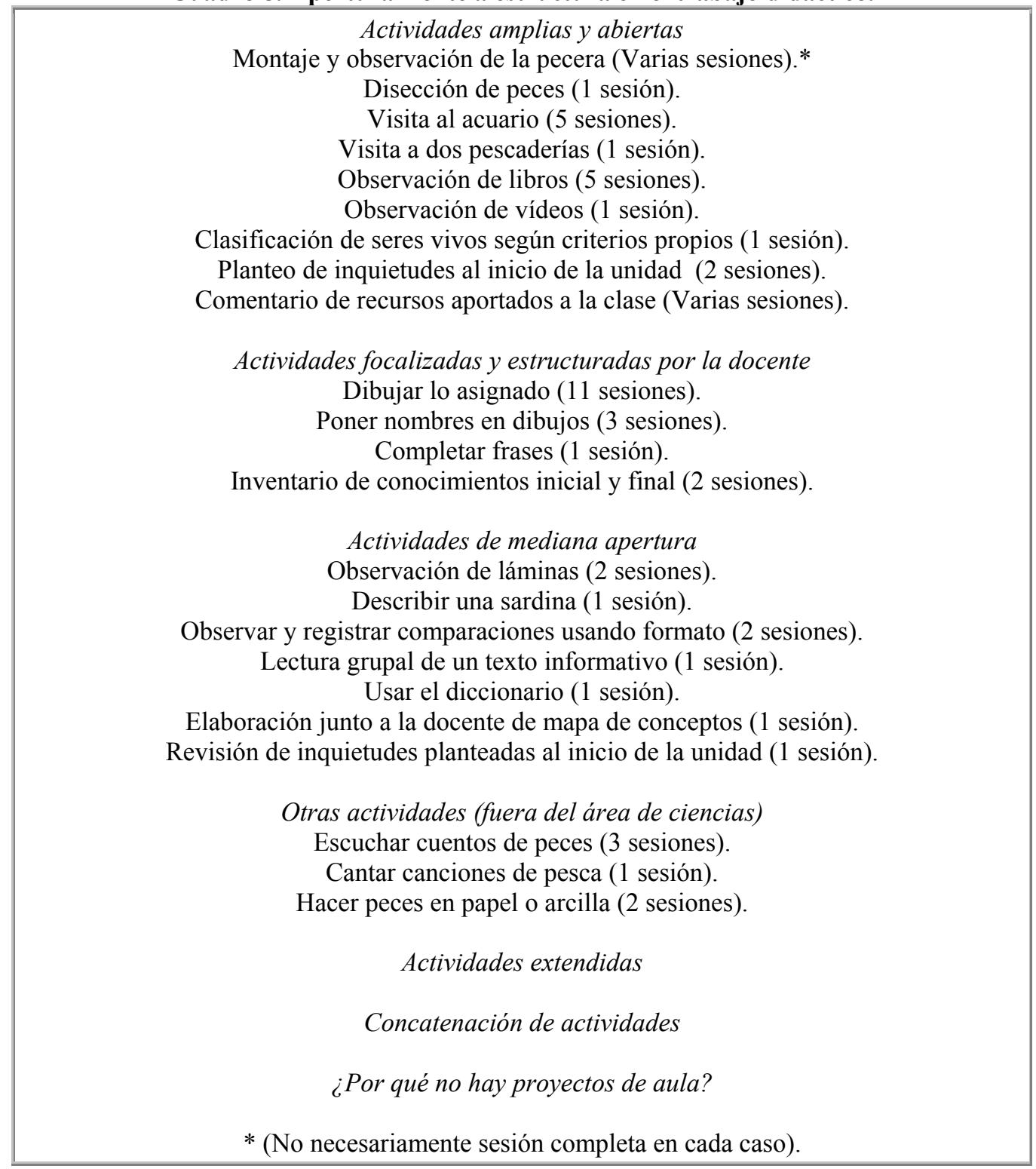

\subsection{Niños y niñas protagonistas}

Estamos acostumbrados a observar en las escuelas un ambiente más bien autoritario, donde los estudiantes juegan un papel pasivo, limitados a seguir siempre instrucciones, vigilados y controlados muy de cerca. Su rol dependiente y constreñido, lleva a través de los años a conformar en muchos estudiantes esa forma de ser y de pensar "del alumno", para quien la escuela es algo ajeno, donde él o ella no tiene ninguna responsabilidad por la buena marcha de las cosas, sino que todo depende de los docentes, quienes para ser buenos deben tener un rasgo casi mágico que se conoce como "dominio de grupo" y que consiste básicamente en poder controlar y mandar a los demás, aun a contra-corriente. En "Los Tres Osos" han construido un ambiente y una forma de vida diferentes, basados en la participación activa y en la toma de decisiones a menudo democrática. Incluso los niños y niñas de Primer Grado, con ser tan pequeños, tienen responsabilidades $\mathrm{y}$ derechos y participan en algunas decisiones $\mathrm{y}$ acciones. 
Semanalmente se rotan los encargados de diversas tareas en el aula: regar las plantas, repartir y recoger hojas y materiales, cerrar la puerta y apagar la luz durante el receso y al término de la jornada, entre otras (alimentar a los peces fue responsabilidad infantil también, y se cumplió fielmente). Además, cuando un estudiante necesita un material o instrumento, si no ha sido objeto de reparto general, puede ir a cogerlo de su estante respectivo: hojas blancas, tijeras punta roma, reglas, creyones y otros implementos están al alcance de la mano de los niños y niñas, quienes pueden levantarse de su asiento e ir a buscarlos sin problemas. Comparamos con esas aulas tensas, donde el reparto de unas hojas de colores o de unas tijeras se convierte en un desbarajuste, pues todo el mundo quiere la suya a la vez, incluso por temor a que se acaben, y gritan a la maestra estirando los brazos.

Los niños y niñas que van terminando una actividad común pueden ir al rincón de biblioteca sin necesidad de pedir permiso, allí leen libros de su escogencia mientras el resto de la clase concluye su labor. Observamos que generalmente no se altera el orden del aula al salir la maestra del salón. Subir y bajar las escaleras se hace con bastante tranquilidad, y el comportamiento en el patio no es agresivo ni escandaloso. Consideramos que las potestades que van asumiendo ayudan a los estudiantes a ser más serios y responsables dentro de la escuela, que perciben también como suya y no sólo de los maestros.

Ha terminado la clase por hoy y todos salen, incluida la maestra, me quedo con la alumna encargada de cerrar, Gracia, quien hábilmente acerca una sillita al interruptor de la luz, se monta y apaga. Luego, se baja y vuelve a poner la silla en su lugar. Salimos y Gracia se empina en punta de pies y mete la llave en la cerradura, insiste un poco hasta que entra completa y luego le da dos vueltas y la saca. Mientras termina, me comenta: "A mí antes me costaba esto".
(Diario de campo, 10-03).

Los saberes que ya tienen los niños y niñas son reconocidos, valorados y utilizados en el plantel. Así, al comenzar a montar la pecera la profesora Marta preguntó quién tenía pecera en su casa, conociéndose que Igor tenía una, y otros niños poseían tortuguitas de agua dulce. A lo largo de este tema fueron destacadas las intervenciones de Igor, un niño que normalmente, según nos señaló la docente, habla muy poco en clase, pero que aquí pudo dar abundante información útil por su interés y conocimiento de las peceras y de los peces marinos, pues al parecer en su familia hay pescadores aficionados, entretenimiento popular en Cataluña.

Los alumnos del plantel ofrecen con regularidad conferencias a los niños y niñas de otros grados acerca de temas que han investigado. Los estudiantes de este curso recibieron una conferencia sobre peces cuando estaban en el Tercer Nivel de Educación Infantil, ofrecida por los niños que entonces cursaban Primer Grado. El contacto intercursos se favorece por otras actividades, como el laboratorio, que se hace con niños de dos grados consecutivos mezclados en secciones ad-hoc.

Por otra parte, a partir de Tercer Grado los niños y niñas celebran una asamblea de clase semanal y también eligen delegados ante una Asamblea Escolar que se reúne periódicamente, y de la cual son miembros, además de los alumnos, el Director, la Jefa de Estudios, el Coordinador de Etapa y la encargada del comedor.

La participación de los propios maestros y maestras es amplia y democrática: periódicamente se rotan en los cargos directivos, quien ha sido director o jefe de estudios vuelve a sus actividades normales como docente $\mathrm{y}$ otro asume su función. El equipo docente (directivos y maestros) se reúne con frecuencia, planifica y toma decisiones. 
La maestra Marta no deja de estar preocupada por conservar el orden: con frecuencia pide silencio con un "Ssshhh" perentorio, apenas el nivel de ruido sube un poco sobre lo normal. Si un niño interviene en clase con digresiones, no duda en cortarlo rápidamente, y el que se mueve mucho en su silla o habla demasiado con el compañero recibirá una llamada de atención. Pero el tono general de la vida en su clase es muy diferente al de esas aulas donde se consume mucha de la energía del educador en mandar callar y estarse quietos a niños díscolos y coaccionados, carentes de auto-disciplina.

El ambiente democrático y responsable en la escuela prepara para el ejercicio cabal de la ciudadanía, a la vez que fomenta un aprendizaje más autónomo y significativo (Goodman, 2001; Lawson, 1994).

\section{Cuadro 9. Niños y niñas protagonistas.}

$>$ Tareas en el aula: regar plantas, repartir y recoger materiales, apagar la luz y cerrar la puerta, cuido de la pecera.

$>$ Recursos al alcance de su mano.

$>$ Decisiones sobre su tiempo extra.

$>$ Reconocimiento de sus saberes: intervenciones puntuales, conferencias a otros gruposclase.

$>$ Actuación como guías de sus padres en visitas al aula.

$>$ Asamblea de clase semanal (a partir de Tercer Grado).

$>$ Delegados a Asamblea Escolar (a partir de Tercer Grado).

$>$ Participación democrática de los docentes.

\subsection{Una escuela de rica vida, más allá del aula}

Además de la variedad de actividades que los estudiantes realizan dentro de su aula, la escuela "Los Tres Osos", como un todo, les ofrece otras iniciativas organizadas y sistemáticas que acrecientan sus experiencias y les ayudan a ampliar sus conocimientos, sus habilidades y sus intereses. Diferentes grados tienen diferentes responsabilidades dentro del plantel: hacer el cartel del tiempo, que está ubicado a la entrada frente a la dirección, coordinar el huerto escolar o ayudar en el comedor, por ejemplo. Los de Primer Grado deben poner diariamente el cartel del almuerzo, ello implica seleccionar entre letreros ya escritos los que corresponden al menú del día, siempre consistente de un primer plato, un segundo plato y un postre. Esta tarea les ayuda a practicar la lectura con un sentido de utilidad, a la vez que colaboran en una labor informativa de la institución.

La escuela posee ambientes diversos, además del aula de clases, que permiten otros aprendizajes con el apoyo de un adecuado mobiliario y unos apropiados recursos. Así, quincenalmente los estudiantes de Primer Grado asisten al laboratorio, dotado de mesones de piedra, agua corriente, gas, aparatos y equipos. Preferimos la actividad experimental integrada a la planificación de aula, pero como un primer paso no nos parece rechazable esta alternativa más sencilla. Una maestra especializada atiende a los pequeños, quienes realizan con ella observaciones y experiencias prácticas diversas, sobre plantas, animales, el agua, la electricidad, entre otros temas. El taller de artes plásticas es otro ambiente visitado, esta vez semanalmente: en sus grandes mesas de madera los niños trabajan con papel, cartulina, arcilla, pintura, disponiendo de multitud de herramientas apropiadas a sus edades. Así, en la clase que vimos sobre "peces de arcilla", había punzones, cuchillos, tenedores, espátulas, todos de madera y no demasiado puntiagudos, junto a tablas, rodillos y buenas cantidades de arcilla, más que suficientes para el trabajo de los pequeños. Sí nos pareció que en este ambiente tan rico la actividad propuesta estuvo demasiado guiada y no ofreció suficientes vías para la expresión original estudiantil. 
En la escuela se desarrolla el programa internacional Filosofía para niños y como el mismo no posee material para Primer Grado, el equipo docente del plantel lo ha elaborado a partir de un libro de cuentos que les pareció apropiado. "Los niños saben que en esta clase discuten de cosas que normalmente no se discuten en ninguna otra clase" (Conversación con M. Montblanc).

Hay libros en cada aula, pero además la escuela cuenta con biblioteca central, que los niños visitan como grupo media hora semanalmente, para devolver libros y pedir otros, que llevan en préstamo a su hogar, también pueden hojear o leer libros en el sitio durante el lapso. Se les prepara una mesa con libros apropiados para ellos, de manera que puedan escoger lo que quieran con más facilidad; en ocasiones, la bibliotecaria les sugiere obras.

La ludoteca es un ambiente nuevo en el plantel, que despierta el entusiasmo de los niños y niñas de Primer Grado. Los alumnos de Educación Infantil también asisten allí. Usualmente, los estudiantes de Primero van una hora los viernes en la tarde. Allí disfrutan de una casita de juguete amueblada, una tienda con artículos diversos de plástico junto a balanza y caja registradora, una minipeluquería, un "taller mecánico", un teatro de títeres, un armario lleno de ropas, pelucas, collares y maquillaje, carritos de madera, todo en un salón amplio, alegre y colorido donde posiblemente los pequeños gozan de buenos ratos, cuyo agrado baña a todo el ambiente y vida escolares: la escuela como un sitio alegre, donde la pasan bien, donde trabajan y también se recrean, en compañía de sus compañeritos y maestros. Creemos que este tono afectivo cálido beneficia mucho el desarrollo de las actividades de enseñanza formal en el aula.

En "Los Tres Osos" se edita una revista para los alumnos, trimestral, donde contribuyen de manera individual o colectiva los estudiantes de los diferentes grados. Hay otra revista bianual para padres y maestros y un boletín trimestral con informaciones puntuales sobre servicios, trámites y eventos, destinado a los padres.

Una actividad muy interesante que nos llamó la atención fue la del Tema de la Semana Cultural del plantel. Cada año, para la semana de la escuela, los estudiantes en conjunto eligen un tema de trabajo. Por ejemplo, dos años atrás había sido escogido "El cine", el año anterior a nuestra observación seleccionaron "El fondo del mar" y el año cuando estuvimos allí el tema fue "Los Dinosaurios". Todos los grados debían contribuir con alguna actividad sobre ese tema, y los resultados de las mismas se exponían luego a lo largo de los espacios escolares: pasillos, escaleras, hall de entrada, etcétera. Así, era llamativo ver en esos días, nada más entrar al plantel, un enorme dinosaurio de cartón y alambres, hecho con la ayuda del profesor de artes plásticas y el padre de un alumno, a partir de un modelo para armar traído por un niño; también había carteleras con textos breves y muchas ilustraciones, incluyendo dibujos de ambientes de nuestro planeta desde que surgieron los dinosaurios hasta hoy; huellas de dinosaurio en el piso de los pasillos y escaleras, que guiaban a las diferentes exhibiciones; sesiones de vídeo referidas al tema; un móvil de dinosaurios en papiroflexia, realizado por alumnos de sexto grado y que, según el director, les consumió bastante tiempo; se observaban además diversos tipos de dinosaurios en plastilina de variados colores, hechos por los niños y niñas de Primer Grado y mostrados con orgullo en el pasillo fuera del aula (a nosotros mismos nos hicieron notar su trabajo). La Semana incluyó conferencias que cada clase daba a otros grupos, la charla de un especialista y una visita al Museo de Paleontología de una ciudad cercana. Este tipo de iniciativa vincula entre sí a los niños y niñas de diferentes grados, convocándolos a compartir el estudio y la comunicación de aprendizajes sobre un tema común, los liga también más a su institución como un todo, haciéndoles sentir parte de una comunidad, y ofrece una oportunidad 
adicional de aprendizaje, más allá de los temas del aula. Nos parece mejor alternativa que la idea de hacer un "Proyecto Pedagógico de Plantel" como se plantea en ocasiones. Un proyecto implica mayor tiempo y trabajo y es difícil así comprometer en un solo tema con tanta exigencia a todos los estudiantes de una escuela. Además, a menudo los temas de estos proyectos son elegidos por los docentes y no por los niños y niñas, reforzando así su papel pasivo dentro de la institución.

El huerto escolar, aunque coordinado por los alumnos de Cuarto Grado, es un ambiente donde todos los alumnos de "Los Tres Osos" pasan algún tiempo al mes. Los de Primer Grado plantan guisantes. Este es un huerto didáctico, de pequeña escala, si bien da frutos y sus productos son consumidos por la comunidad escolar. Por otra parte, las amplias áreas verdes de la escuela se prestan para ciertos estudios, que Marta realiza, según ella explica, de acuerdo a la época del año: los piñones, el olivo, las urracas, las hormigas (abundan en primavera), entre otros.

Diversas festividades a lo largo del año dan pie a algunas actividades interesantes, que vinculan a los niños y niñas con las tradiciones culturales de Cataluña. Así, tuvimos oportunidad de observar en las fechas de nuestra estadía cómo los niños de Primer Grado elaboraron con ayuda de algunas maestras y de la cocinera del plantel un dulce tradicional catalán de Pascua, la "mona": sobre la masa base ya hecha ellos añadieron ingredientes y, luego de horneada, la barnizaron y decoraron. Adicionalmente, el plantel aprovecha oportunidades de nuevas experiencias para los estudiantes que ofrecen otras instancias. Por ejemplo, una mañana los niños de Primer Grado participaron en la "Fiesta de la Primavera" organizada por la alcaldía de su ciudad. Sembraron margaritas en un parque cercano, y recibieron de regalo una plantita y una graciosa visera verde de cartón, que muchos lucieron luego durante todo ese día.

\section{Cuadro 10. Riqueza de la actividad escolar extra-aula.}

\begin{tabular}{l}
\hline Cartel del tiempo \\
$>$ Cartel del almuerzo \\
$>$ Huerto escolar \\
$>$ Ayudantes en el comedor \\
$>$ Laboratorio \\
$>$ Taller de artes plásticas \\
$>$ Ludoteca \\
$>$ Biblioteca \\
$>$ Programa "Filosofía para niños" \\
$>$ Revista de los niños \\
$>$ El gran tema de la Semana Cultural \\
$>$ Las áreas verdes \\
$>$ Celebración de ciertas festividades: Pascua \\
$>$ Aprovechamiento de experiencias ofrecidas por otras instancias: "Fiesta de la Primavera"
\end{tabular}

\subsection{La multifacética relación escuela- hogar}

"Los Tres Osos" cultiva la relación con los padres y la amplía hacia facetas poco atendidas tradicionalmente. Los padres participan en el Consejo Escolar desde la fundación del plantel, antes de que fuera legalmente reque- rido, incluso en aquella época su participación era paritaria, hoy la Ley establece un $50 / 50$ pero cuenta aparte a los directivos para formar el Consejo. Se elabora para los padres y con su colaboración un boletín y una revista y, como ya mencionamos, son tomados en cuenta para el desarrollo del tema de estudio de La Semana Cultural de la Escuela. 
Cada mes o mes y medio, unos treinta minutos antes de culminar la jornada del viernes se invita a los padres y/o representantes a que visiten el aula de su representado. Presenciamos este evento en el salón de la profesora Marta: vinieron varios representantes, sobre todo madres, abuelas y algún abuelito. Incluso, a veces, acuden hermanos mayores, según nos comentó la educadora. Cada estudiante guiaba a su familiar por el aula, mostrándole novedades (la pecera, un cartel de números donde todos habían colaborado, los recursos traídos por los niños para el tema de peces, algún libro bonito de la biblioteca, los trabajos en arcilla...) y culminando luego en su propio dossier de trabajo, con las producciones más recientes. Esta actividad permite a los padres conocer más profunda y completamente el trabajo de su hijo o hija y la índole de la actividad escolar. Además, el hecho de que sean los propios niños y niñas quienes conduzcan la visita es una nueva oportunidad de darles esa importancia y protagonismo que antes hemos destacado. Adicionalmente, les ayuda a ganar una perspectiva metacognitiva de su aprendizaje, lo ven en conjunto y deben destacar de él aspectos interesantes y relevantes, y comentarlos con sus padres, respondiendo a sus posibles preguntas: lo que hice, cómo lo hice, qué me parece. Claro que en Primer Grado esta actividad es más bien breve, y algunos alumnos poco expresan de su labor, pero sin embargo se realiza.

Otro mecanismo muy relevante de vinculación escuela-hogar es a través de los recursos que los niños deben traer para enriquecer cada unidad didáctica. Esta asignación implica participación de los padres en la búsqueda de algo interesante que tengan en casa y que pueda servir para el tema. En "Los Peces" observamos cómo los niños aportaron una variedad de elementos: peces de goma, peces de fieltro, libros, vídeos, postales... Algunos recursos podían resultar más útiles o interesantes que otros, pero la maestra los valoraba todos. En el caso de los vídeos, como eran muy largos para observarlos sin más, Marta los veía primero sola y seleccionaba un pedazo particularmente apropiado, para ser proyectado en aula. Es un trabajo adicional de la educadora con el fin de enriquecer la vida de los alumnos y de estimular su participación y la de sus familias.

También nos parece muy positiva la práctica, común en esta escuela, de invitar a los padres y madres $u$ otros familiares a hablar en clase sobre temas de su conocimiento. En la unidad didáctica de "Los Peces" no hubo oportunidad de ello, pero en la unidad anterior, "La Casa", participaron un padre albañil y otro electricista. Esta estrategia relaciona más estrechamente a los padres con la escuela, a la vez que los valoriza, independientemente de que no todos sean profesionales universitarios ni expertos consagrados. Adicionalmente, los estudiantes se benefician de los saberes y perspectivas del padre o madre experto o experta. Ellos contribuyen a transferir aprendizajes escolares al mundo más allá del aula (Bransford y otros, 2000).

Se realiza una entrevista al año con cada representante, y más si resulta necesario. El mayor conocimiento docentes-padres y la vinculación de los padres con la institución se refuerza con la celebración de algunas festividades. Así, en la fiesta de la patrona de la localidad (Festa Major) hay una paellada en el centro, desarrollada con activa participación de los padres.

La relación escuela-hogar en "Los Tres Osos" está signada por tres grandes rasgos: información suficiente y oportuna, diálogo abierto y colaboración diversificada. 
Cuadro 11. Multifacética relación escuela-hogar.

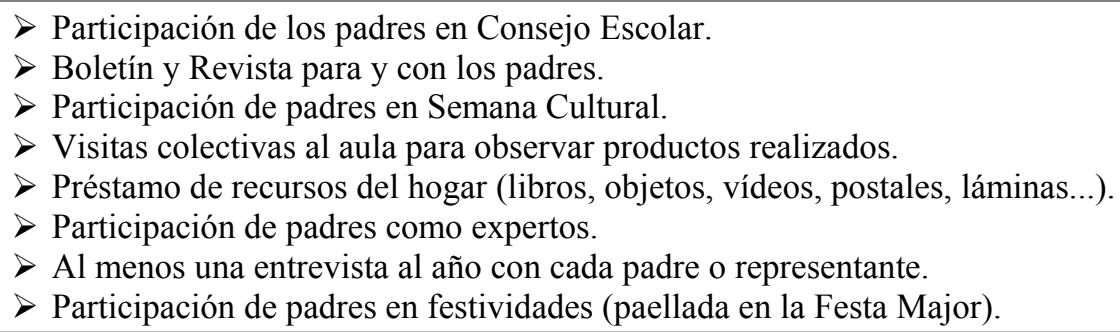

\section{6. ¿Qué aprendieron los niños?}

Dada la complejidad de cada mente humana y nuestros escasos conocimientos de su funcionamiento, no hay quien pueda responder a esta pregunta con precisión. Los intentos de hacerlo sólo gracias a un pre-test y a un post-test de inevitable limitado alcance nos parecen realmente fútiles. Sin embargo, contamos con variada información que nos ofrece aproximaciones parciales.

En primer lugar, es de destacar que las sesiones de clase eran bastante tranquilas $y$ productivas: la gran mayoría de los estudiantes se mantenían ocupados en su labor buena parte del tiempo y lograban culminar los trabajos asignados. Esto para algunos puede parecer obvio, pero habiendo presenciado sesiones verdaderamente caóticas en gruposclase numerosos, de 37 ó 38 alumnos, en escuelas públicas de población pobre, valoramos el ambiente tranquilo y laborioso del aula de Marta Montblanc. Aquí existen, de entrada, condiciones para aprender algo: tranquilidad, aplicación a la labor, trabajo sistemático a lo largo no de retazos de tiempo sino de toda la jornada escolar.

Pasando a evidencias concretas, podemos señalar que Marta buscaba fomentar las intervenciones orales de los alumnos en el transcurso de la unidad didáctica y tuvo éxito en ello: siempre que lanzaba preguntas al grupo diversos estudiantes alzaban su mano y ofrecían respuestas. No todos intervenían espontáneamente, sin embargo, y la profesora dirigía de vez en cuando preguntas a estudiantes específicos. Estas preguntas eran a veces muy puntuales, e indagaban sobre el nombre de, por ejemplo, la aleta situada en el lomo del pez o las estructuras que le permiten al pez respirar. En otras oportunidades las preguntas eran más complejas y ayudaban a recordar y organizar lo observado en las visitas, o inquirían por conocimientos extra-escolares de los niños y niñas que estaban vinculados al tema, o pedían reflexionar sobre un asunto determinado y ofrecer aportes. Siempre, tanto en preguntas cerradas como abiertas, de memorización o de reflexión, la profesora obtuvo respuestas, no todas correctas aunque sí a menudo entusiastas: la mayoría de los alumnos atendían a sus interrogantes y se mostraban interesados en participar.

“Qué debemos vigilar en la pecera?” pregunta la maestra Marta. Y los estudiantes van pidiendo la palabra y responden: "Que no caiga, que no se mueran los peces, que no se mueva la mesa, ponerle poca comida, no tocar las plantas, vigilar si hay hijitos, no meter los dedos en el agua, vigilar cuando crezcan para sacarlos de la 'paridera'”.

"Faltan cosas importantes", dice Marta. Entonces se empiezan a parecer más las respuestas: "No tocar el vidrio, no meter cosas adentro..."

“ ¿Esta agua estará siempre igual de alta?", corta la maestra Marta, señalando el nivel del agua del acuario.

"No, se evapora", afirma una niña. A lo que la maestra añade: “ ¿Y dónde está el agua que se evapora?", y ella misma se 
responde, indicando con las manos el conjunto del aula: "Por todo esto". La niña que habia intervenido antes completa: " $Y$ luego cuando se enfría baja, me lo ha explicado mi abuelo".

(Síntesis de notas de campo, 09-03).

Son interesantes no sólo las respuestas sino también las preguntas infantiles. Al plantear la profesora que discutieran por equipos lo que querían saber de los peces, surgieron treinta preguntas, muchas de las cuales, como mencionamos anteriormente, fueron atendidas de una u otra manera a lo largo de la unidad, entre ellas: por dónde respiran, cómo son las espinas y por qué tienen tantas, cómo es el corazón, cómo y por dónde nacen, qué comen, cómo nadan, cómo flotan, cómo duermen, si la medusa es un pez... Otras fueron pospuestas por la profesora Marta "para años superiores": por qué es salada el agua del mar, desde cuándo existen los peces, si hay peces dinosaurios... Aunque esta última ella la comentó un poco, dado que era el tema de la Semana Cultural, y señaló que sí había dinosaurios en el mar, respuesta que quizá se prestaba a confusión, dado que los dinosaurios eran reptiles.

Conforme fue desarrollándose la unidad didáctica, aumentaron las intervenciones estudiantiles correctas acerca de los diversos puntos que la profesora Marta se había plan- teado en su planificación: definiciones de ser vivo, vertebrado y pez, partes de un pez por fuera y por dentro, nombres de peces, diferenciación entre peces y otros conocidos animales marinos que no son peces.

Este progreso pudo notarse también comparando los dibujos del pez por fuera y el pez por dentro hechos por los estudiantes al principio y al final de la unidad didáctica. Y contrastando las actividades escritas. Recogimos muestras de trabajos de niños considerados por la profesora avanzados, de rendimiento medio y con dificultades. Notamos que en todos los casos hubo mejoras: al final se dibujaron y nombraron más estructuras, tanto de la anatomía interna como externa. Así mismo, se nombraron más peces y se diferenciaron mejor de animales acuáticos que no son peces. En el dibujo inicial del pez por fuera y por dentro, de ocho alumnos cuyos trabajos recogimos sólo tres señalaron algunos nombres de estructuras; mientras que en el dibujo final los siete seleccionados lo hacen, indicando de dos a catorce partes, y sus ilustraciones son más realistas y completas (ver resumen general preparado por la maestra en el cuadro 12). Debemos notar que entre las cosas difíciles del tema de "Peces", tres niños de los seis entrevistados mencionaron "saber las partes de un pez por dentro". 
Cuadro 12. El pez por fuera, el pez por dentro.

Vaciado de los dibujos de los alumnos, realizado por M. Montblanc.

\begin{tabular}{|c|c|c|c|c|c|c|c|c|c|c|c|c|c|c|c|c|c|c|c|c|c|c|c|c|}
\hline & \multicolumn{12}{|c|}{ EVALUACIÓN INICIAL } & \multicolumn{12}{|c|}{ EVALUACIÓN FINAL } \\
\hline & & & & & & & & & & & & & & & & & & & & & & & & \\
\hline & 1 & 2 & 3 & 4 & 5 & 6 & 7 & 8 & 9 & 10 & 11 & 12 & 1 & 2 & 3 & 4 & 5 & 6 & 7 & 8 & 9 & 10 & 11 & 12 \\
\hline Gilbert A. & & & & & & & & & & & & & $*$ & $*$ & $*$ & $*$ & $*$ & $*$ & $*$ & $*$ & $*$ & $*$ & $*$ & $*$ \\
\hline Gilbert B. & 0 & 0 & 0 & 0 & & 0 & & & & 0 & & & - & - & - & - & - & - & - & - & - & - & - & - \\
\hline Ainhoa $\bullet$ & & 0 & & 0 & & 0 & & & & & & & $*$ & $*$ & $*$ & $*$ & $*$ & $*$ & & $*$ & & $*$ & & $*$ \\
\hline Adriana & & & & & & 0 & & & & & & & - & - & - & - & - & - & - & - & - & - & - & - \\
\hline Oscar & & & & & & & & & & & & & - & - & - & - & - & - & - & - & - & - & - & - \\
\hline Amèlia • & 0 & 0 & 0 & & & 0 & & & & & & & & $*$ & $*$ & $*$ & $*$ & $*$ & $*$ & $*$ & & & & $*$ \\
\hline Mercè & & & 0 & 0 & & 0 & & & & & & & & $*$ & $*$ & $*$ & & $*$ & & $*$ & $*$ & & & \\
\hline Toby & & & 0 & 0 & & & & & & & & & & $*$ & $*$ & $*$ & & $*$ & & $*$ & & & & $*$ \\
\hline Igor & & & & & & & & & & & & & & & $*$ & $*$ & $*$ & $*$ & $*$ & $*$ & & $*$ & & \\
\hline Dalia & & 0 & 0 & 0 & & 0 & & & & & & & & $*$ & $*$ & $*$ & $*$ & $*$ & & $*$ & & $*$ & & \\
\hline Gracia & & & & & & & & & & 0 & & & $*$ & $*$ & $*$ & $*$ & $*$ & $*$ & & & & $*$ & & \\
\hline Ramón • & 0 & 0 & & & & 0 & & & & & & & & $*$ & $*$ & $*$ & $*$ & $*$ & & $*$ & & $*$ & $*$ & $*$ \\
\hline Elionor • & & 0 & 0 & 0 & & 0 & & & & & & & & $*$ & $*$ & $*$ & & $*$ & & & & & & $*$ \\
\hline Feli & & 0 & 0 & 0 & & 0 & & & & & & & & $*$ & $*$ & & $*$ & $*$ & $*$ & $*$ & & $*$ & $*$ & $*$ \\
\hline Mateu & & 0 & & & & 0 & & & & & & & & $*$ & & & & $*$ & & $*$ & & $*$ & & \\
\hline Horaci & & & & & & & & & & & & & & $*$ & $*$ & $*$ & $*$ & $*$ & & $*$ & & $*$ & & $*$ \\
\hline Florencia & & 0 & & 0 & & & & & & & & & $*$ & $*$ & & $*$ & & $*$ & & & & & & \\
\hline TOTAL & 3 & 9 & 7 & 8 & $\mathbf{0}$ & 10 & $\mathbf{0}$ & $\mathbf{0}$ & 0 & 2 & 0 & 0 & 4 & 13 & 12 & 12 & 9 & 14 & 4 & 11 & 2 & 9 & 3 & 8 \\
\hline $\begin{array}{l}\text { 1: Dientes } \\
\text { 2: Aletas } \\
\text { 3: Opérculos } \\
\text { 4: Escamas } \\
\text { 5: Línea sen } \\
\text { 6: Espinas }\end{array}$ & soria & & & $\begin{array}{l}\text { 7: B } \\
\text { 8: C } \\
9: \mathrm{H} \\
\text { 10: I } \\
\text { 11: V } \\
12: A\end{array}$ & $\begin{array}{l}\text { anq } \\
\text { raz } \\
\text { gad } \\
\text { test } \\
\text { ejig } \\
\text { no }\end{array}$ & $\begin{array}{l}\text { lias } \\
\text { n } \\
\text { no } \\
\text { nat }\end{array}$ & tori & & & & & & & & & & & & & & & & & \\
\hline
\end{tabular}

- Otras estructuras señaladas en Evaluación Final:

Ainhoa: musculatura, cráneo

Amèlia: ovario

Ramón: Musculatura

Elionor: Musculatura

La pecera del aula fue atentamente observada por todos en múltiples ocasiones y las novedades eran discutidas: la aparición de caracoles, el que a una planta se le pusieran las puntas marrones, cómo se alimentaban al lanzarles la comida, cómo se movían, los huevos negros en el vientre de las hembras translúcidas $\mathrm{y}$, sobre todo, la aparición de los nuevos pececitos.

También fue seguida con concentración la disección del pez, excepción hecha de un niño que tenía rechazo a ver este espectáculo. En esa clase los niños hicieron variados comentarios y preguntas. La disección era recordada en la entrevista final, aunque con cierto reparo, por estar involucrada la sangre y el manejo de un organismo muerto. Como dijo Gracia: "Es que están muy pachuchos cuando están muertos". (Entrevista final alumnos Gracia y Mateu).

La visita al acuario fue un evento atendido con gran cuidado por los pequeños, durante el cual plantearon preguntas e incluso repreguntaron. Los dibujos y escritos hechos $a$ posteriori en clase eran ricos en detalles sobre peces diversos y otros animales marinos. Durante las entrevistas finales que tuvimos con tres parejas de niños y niñas todos mencionaron la visita al acuario como una de las 
cosas que más les gustó de esta unidad didáctica. Los pequeños espontáneamente nos comentaron nombres y características de peces allí vistos. Nos llamó la atención que una niña, Amèlia, nos preguntó de pronto al hablar del acuario en su entrevista: "¿Tú sabías que el caballito de mar era un pez?".

Estimamos que durante la unidad didáctica los estudiantes pudieron seguir avanzando en su dominio de procedimientos para trabajar de manera individual, en equipo y en discusión general: no hacían ruido, levantaban la mano para intervenir, se escuchaban bastante unos a otros $\mathrm{y}$, en equipo, aunque algunos no trabajaban casi todos colaboraban al menos parte del tiempo. Los que no seguían estos procedimientos recibían reclamos de otros compañeros o de la maestra. Así mismo, todos compartieron responsabilidades en el cuidado del acuario y muchos aportaron recursos para el trabajo en la unidad. Lamentamos la poca consideración sistemática en la unidad de procedimientos complejos importantes, como formular hipótesis, diseñar experimentos, interpretar resultados, así como, en otra dimensión investigativa, deliberar sobre asuntos socio-científicos, tomar decisiones y llevar algunas a la práctica, evaluando luego logros.

Los alumnos de Montblanc cumplimentan un inventario de conocimientos tanto al inicio como al final de las principales unidades didácticas del año. Los niños y niñas lo conocen y ya saben cómo llenarlo; la docente va leyendo las preguntas, en este caso nueve, y a cada una los estudiantes marcan en su hoja: verde si la saben, anaranjado si la saben más o menos y rojo si no conocen el asunto.

En la unidad didáctica "Los Peces", el inventario inicial de conocimientos le sirvió a la profesora Marta, según ella indica, para "obtener información sobre lo que creen saber ellos (los estudiantes) de este tema", y añade:

Otra vez más, me ha sido útil reflexionar cómo son de importantes las ideas o conocimientos previos de los alumnos para poder organizar un tema. Este grupo, debido al trabajo realizado el curso anterior en la Semana Cultural, cuyo tema era el fondo del mar, tiene unos conocimientos previos más ricos.

(Diario de la docente, semana 1).

En una de las últimas clases de la unidad, los alumnos contaron las respuestas en verde de los inventarios inicial y final para constatar "si habían aprendido más cosas", como dijo una niña. Las respuestas en verde habían aumentado significativamente y quedaban muy pocas en naranja o rojo (ver cuadro 13). Aunque también hay que tener en cuenta, como la profesora Marta nos explicó, que a veces una respuesta en naranja es un avance con respecto a un verde, pues implica que un niño o una niña que creía saber algo muy bien se ha percatado al continuar en su aprendizaje de que hay mucho más por conocer de lo que al principio pensaba. Así lo reconoce Poddiákov (1987), cuando expresa que al ahondar en el estudio las certezas pueden dar paso a nuevas dudas, y ésa es la compleja dinámica del aprendizaje. 
Cuadro 13. Vaciado de los inventarios inicial y final de la U. D. "Los Peces". Realizado por M. Montblanc.

$$
\text { EL PEZ - K.P.S.I. }
$$

1. ¿Sabes si el pez es un ser vivo? 2. ¿Sabes si el pez tiene huesos?

3. ¿Sabes de qué está cubierto el cuerpo del pez? 4. ¿Sabes cómo respiran los peces?
6. ¿Sabes para qué le sirven las aletas?

7. ¿Sabes cómo nacen los peces?

8. ¿Sabes qué se necesita para montar un acuario?

5. ¿Sabes qué es el opérculo?

\begin{tabular}{|c|c|c|c|c|c|c|c|c|c|c|c|c|c|c|c|c|c|c|c|c|c|c|c|c|c|c|c|}
\hline & \multicolumn{3}{|c|}{1} & \multicolumn{3}{|c|}{2} & \multicolumn{3}{|c|}{3} & \multicolumn{3}{|c|}{4} & \multicolumn{3}{|c|}{5} & \multicolumn{3}{|c|}{6} & \multicolumn{3}{|c|}{7} & \multicolumn{3}{|c|}{8} & \multicolumn{3}{|c|}{9} \\
\hline & A & B & $\mathrm{C}$ & A & $\mathrm{B}$ & $\mathrm{C}$ & A & B & $\mathrm{C}$ & A & B & $\mathrm{C}$ & A & B & $\mathrm{C}$ & A & B & $\mathrm{C}$ & A & $\mathrm{B}$ & C & A & B & $\mathrm{C}$ & A & B & $\mathrm{C}$ \\
\hline Gilbert A & o* & & & $\mathrm{O}^{*}$ & & & $\mathrm{O}^{*}$ & & & o* & & & * & & $\mathrm{o}$ & o* & & & $\mathrm{o}^{*}$ & & & $\mathrm{O}^{*}$ & & & $*$ & & $\mathrm{o}$ \\
\hline Gilbert B & 0 & & & 0 & & & $\mathrm{o}$ & & & 0 & & & & $\mathrm{o}$ & & 0 & & & $\mathrm{o}$ & & & 0 & & & & & $\mathrm{O}$ \\
\hline Ainhoa & o* & & & $*$ & $\mathrm{o}$ & & $*$ & & $\mathrm{o}$ & & O* & & * & & $\mathrm{o}$ & o* & & & * & & $\mathrm{o}$ & * & o & & $*$ & & $\mathrm{o}$ \\
\hline Adriana & 0 & & & $\mathrm{O}$ & & & $\mathrm{o}$ & & & $\mathrm{O}$ & & & & & $\mathrm{o}$ & 0 & & & & & $\mathrm{o}$ & $\mathrm{O}$ & & & . & & $\mathrm{O}$ \\
\hline Oscar & $\mathrm{o}$ & & & $\mathrm{o}$ & & & $\mathrm{o}$ & & & $\mathrm{o}$ & & & & & o & $\mathrm{O}$ & & & $\mathrm{O}$ & & & o & & & & & $\mathrm{o}$ \\
\hline Amèlia & o* & & & * & $\mathrm{O}$ & & o* & & & $*$ & & $\mathrm{o}$ & $*$ & & $\mathrm{o}$ & o* & & & * & & 0 & & $*$ & 0 & $*$ & & $\mathrm{o}$ \\
\hline Mercè & o* & & & $*$ & & 0 & $*$ & & o & o & & * & & & o* & o* & & & $*$ & & o & & o & * & $*$ & & o \\
\hline Toby & o* & & & o* & & & * & & o & $\mathrm{o}^{*}$ & & & & & o* & 0 & & $*$ & $\mathrm{o}^{*}$ & & & $\mathrm{o}^{*}$ & & & o* & & \\
\hline Igor & $\mathrm{o}^{*}$ & & & o* & & & $\mathrm{O}^{*}$ & & & $\mathrm{O}^{*}$ & & & $*$ & & 0 & o* & & & $*$ & o & & * & o & & $\mathrm{o}^{*}$ & & \\
\hline Dalia & $\mathrm{o}^{*}$ & & & $*$ & $\mathrm{o}$ & & $*$ & & o & & $\mathrm{O}^{*}$ & & * & & $\mathrm{o}$ & o* & & & $*$ & & o & * & 0 & & $*$ & & 0 \\
\hline Gracia & 0 & * & & o* & & & $\mathrm{O}^{*}$ & & & 0 & & $*$ & $*$ & & $\mathrm{o}$ & 0 & $*$ & & $*$ & 0 & & * & 0 & & $*$ & & $\mathrm{o}$ \\
\hline Ramón & $\mathrm{O}^{*}$ & & & $*$ & $\mathrm{o}$ & & $\mathrm{O}^{*}$ & & & $\mathrm{O}^{*}$ & & & * & & $\mathrm{o}$ & $\mathrm{O}^{*}$ & & & $\mathrm{o}^{*}$ & & & $\mathrm{o}^{*}$ & & & $\mathrm{O}^{*}$ & & \\
\hline Elionor & 0 & $*$ & & * & 0 & & $*$ & & $\mathrm{O}$ & & * & 0 & & $*$ & 0 & $\mathrm{O}^{*}$ & & & & $*$ & 0 & & $\mathrm{o}^{*}$ & & $*$ & & o \\
\hline Feli & $\mathrm{o}^{*}$ & & & o* & & & $\mathrm{O}^{*}$ & & & $\mathrm{o}^{*}$ & & & * & & o & o* & & & $*$ & & o & o* & & & $*$ & & o \\
\hline Mateu & $\mathrm{O}^{*}$ & & & $\mathrm{O}^{*}$ & & & $\mathrm{O}^{*}$ & & & $\mathrm{O}^{*}$ & & & $*$ & & 0 & $\mathrm{O}^{*}$ & & & * & & \begin{tabular}{l|l}
0 \\
\end{tabular} & & $\mathrm{o}^{*}$ & & $*$ & & 0 \\
\hline Horaci & $*$ & & & $*$ & & & $*$ & & & $*$ & & & $*$ & & & & & & $*$ & & & * & & & $*$ & & \\
\hline Florencia & 0 & & * & $*$ & & 0 & & & $\mathrm{O}^{*}$ & 0 & & $*$ & & & $\mathrm{o}^{*}$ & $\mathrm{O}^{*}$ & & & $*$ & & 0 & & & $\mathrm{O}^{*}$ & & & $\mathrm{o}^{*}$ \\
\hline $\begin{array}{c}\text { Inicio } \\
16 \text { niños } \\
\end{array}$ & 16 & 0 & 0 & 9 & 5 & 2 & 10 & 0 & 6 & 12 & 2 & 2 & 0 & 1 & 15 & 16 & 0 & 0 & 5 & 2 & 9 & 7 & 7 & 2 & 3 & 0 & 13 \\
\hline $\begin{array}{c}\text { Fin } \\
14 \text { niños }\end{array}$ & 11 & 2 & 1 & 14 & 0 & 0 & 13 & 0 & 1 & 8 & 3 & 3 & 10 & 1 & 3 & 12 & 1 & 1 & 13 & 1 & 0 & 9 & 3 & 2 & 13 & 0 & 1 \\
\hline
\end{tabular}

\section{A: LO SÉ}

B: LO SÉ UN POCO

C: NO LO SÉ

Nos llamó la atención la manera aparentemente cuidadosa y reflexiva como los estudiantes llenaron el inventario en ambas oportunidades: trabajaron en silencio, dedicándole tiempo a cada interrogante, y cambiando de creyón según el caso.

Luego de terminar el inventario final, la profesora volvió a dialogar en clase sobre las preguntas que algunos habían respondido todavía en rojo ("No lo sé") o naranja ("Lo sé un poco"): “¿Sabes qué es un ser vivo?”, “Sabes cómo respiran los peces?”, “Sabes o: EVALUACIÓN INICIAL

*: EVALUACIÓN FINAL qué es el opérculo?". En todos los casos, otros niños explicaron la respuesta correcta a sus compañeros.

Maestra Marta (M): -Un ser vivo... ¿cuáles son las cosas más importantes de un ser vivo?

(De los seis niños que se ven en el vídeo, Ainhoa alza la mano rápidamente, pero Marta da la palabra a otro alumno de una mesa que no se ve).

Alumno 1 (A1): -Que se alimenta. 
M: -¿Se alimenta para qué?

A1: (Dice algo que no se grabó).

M: -Para vivir. ¿Qué más?

A2: -Respira.

M: -Respira.

A3:-Vive.

M: -Vive. Pero para vivir hace todo eso.

A4: -Si y...

M:-Ssshh. Tú no levantes la mano.

(No se ve, pero debe ser alguien que ya ha hablado durante la sesión).

A5:-Muere.

M: -Muere. Pero primero, ¿qué ha de hacer?

A5: -Nace.

M: -Nace. Muy bien. Vive, para vivir se alimenta y respira y se muere... y me falta una cosa...

A6: -Nace.

M: -Nace, pero para nacer ¿qué necesita?
A7: -Alimentarse...

M: ¿¿Cómo puede nacer el pez?

A8: -Yo sé, yo sé... Se... Juntarse. (Hace gesto juntando las dos manos).

M: -Juntarse. Muy bien.

(Transcripción vídeo, clase del 22-03).

La sesión final de revisión de la lista de preguntas de "¿Qué queremos saber de los peces?" permitió volver sobre los conceptos perseguidos por Marta y sobre otros temas planteados por los niños. Hubo variadas intervenciones infantiles comentando las respuestas.

La realización guiada del mapa de conceptos colectivo (figura 4) fue en realidad como un nuevo interrogatorio algo reiterativo, pero por la novedad del contexto los niños y niñas la asumieron con interés y bastante participación, con intervenciones acertadas. Incluso el acto de escritura de la profesora sobre el pliego de papel era seguido por los pequeños con atención, suponemos por ser la escritura algo bastante nuevo para ellos. En ocasiones, repetían a coro en voz baja la palabra que Marta estaba escribiendo: "Oooouuussss" (Huevos). 
Fig. 1. Mapa de conceptos sobre los peces, elaborado por M. Montblanc y sus alumnos

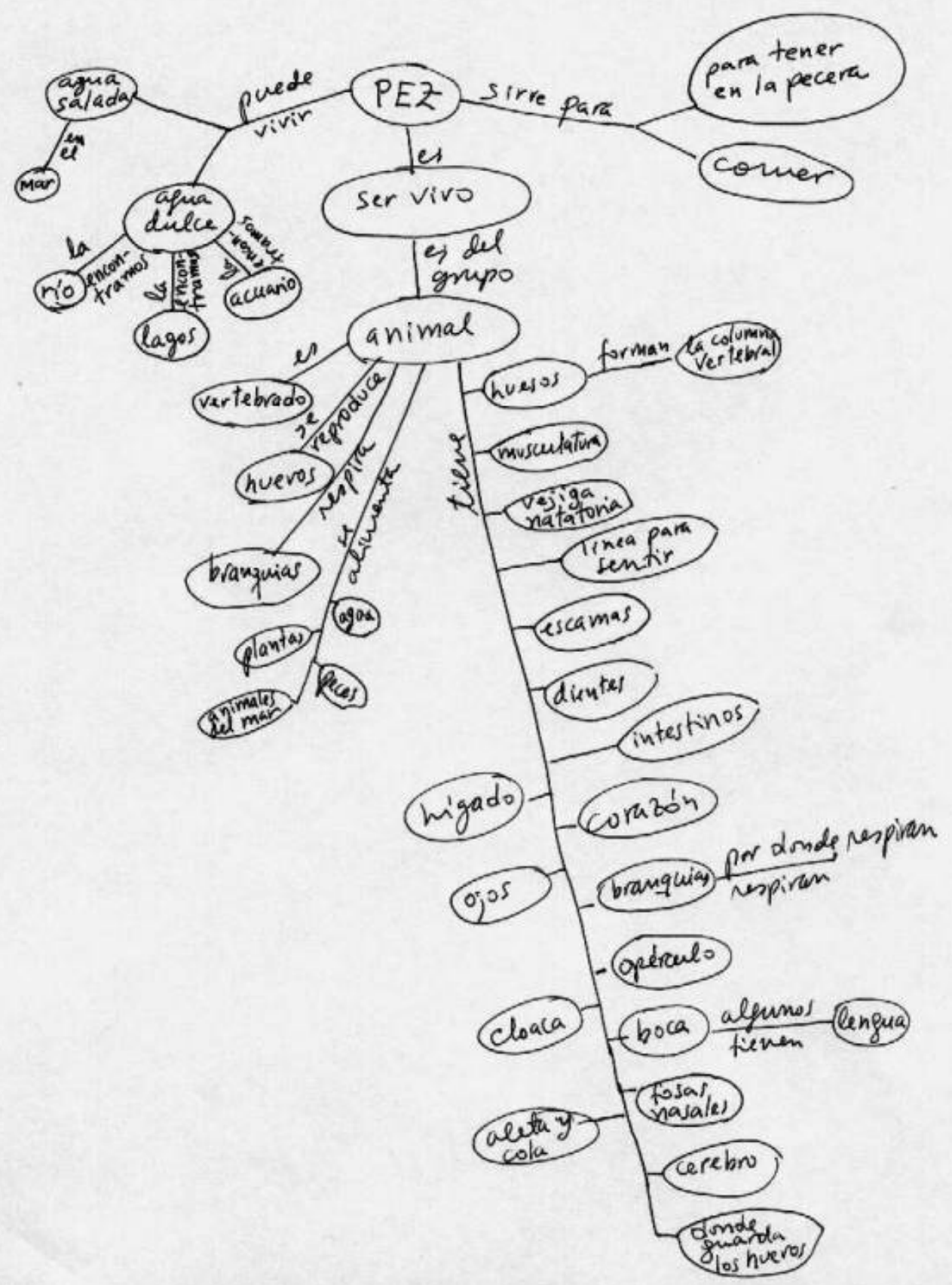

Claro que todo estaba todavía en desarro1lo. Así, el 16 de Marzo, en la semana 3 de trabajo, Marta pregunta por escrito (Actividad: "Descripción de una sardina”): “Cómo sabeis que una sardina es un pez?", y un equipo responde: "Porque vive en el mar, porque nada, tiene branquias, porque tiene aletas". Pero otros dicen: "Porque la he co- mido y se parece mucho a un pez". Aunque luego añaden que tiene aletas y tiene cola.

Los elementos que hemos mencionado nos orientan acerca de los posibles aprendizajes de los niños y niñas durante este tema. Por su parte, la profesora Marta expresó las siguientes consideraciones: 
Me sorprende los conocimientos y el vocabulario que son capaces de aprender los niños y las niñas.

(Diario de la docente, semana 3).

En general, se han conseguido los objetivos previstos y en algún aspecto se han superado.
(Diario de la docente, semana 4).

\section{(...) Cómo realmente les ha llegado a in-} teresar el tema, eso me ha sorprendido. (...) Pero pienso que, aparte de motivarlos, a nivel científico han adquirido muchos conocimientos. (...) No quiere decir que los tengan ya consolidados (assolits).

(Entrevista final M. Montblanc).

Cuadro 14. Evidencias directas e indirectas del aprendizaje infantil.

$>$ Ambiente de clase tranquilo y productivo.

$>$ Participación mayoritaria en discusiones guiadas (corrección en respuestas aumentó a lo largo de la unidad).

$>$ Planteo de interrogantes diversas y abundantes.

> Avances generales en dibujos finales del pez por fuera y el pez por dentro.

$>$ Avances en inventario de conocimientos (de inicial a final).

$>$ Participaciones positivas en discusión general sobre inventario final.

$>$ Participaciones positivas en revisión final de preguntas “¿Qué queremos saber?”.

> Participación positiva en realización guiada del mapa de conceptos.

$>$ Observación atenta a: pecera, disección de pez, visita a acuario, visita a pescaderías. Emisión de preguntas y comentarios.

$>$ Recuerdo de lo observado en actividades posteriores: dibujos, escritos, comentarios orales.

> Positivos procedimientos de trabajo individual, en equipo y general: respeto, responsabilidad, organización, colaboración (hay avances, de acuerdo a la docente)

\section{Conclusiones}

La observación y reflexión sobre la escuela "Los Tres Osos" y el trabajo en ella de la profesora Marta Montblanc nos permiten establecer o reafirmar ciertas ideas-fuerza que presentamos aquí como conclusiones.

\subsection{Pensar la escuela como un ecosiste- ma}

La enseñanza es una actividad difícil y compleja, y es necesario atender simultáneamente a múltiples factores para que ella resulte verdaderamente exitosa. Los cambios puntuales y aislados posiblemente no logran el impacto deseado, si su contexto de aplicación no les es suficientemente favorable. Por ello, y siguiendo el ejemplo del plantel observado, resulta importante el trabajo en equipo de directivos y docentes para pensar la escuela como un todo, para desarrollarla como un "ecosistema" sano y estimulante, concebido para favorecer al máximo el aprendizaje infantil. Ambientes, recursos, organización, actividades intra-aula y extraaula deben analizarse según su estímulo a la formación más completa de los niños y niñas, y su coherencia y refuerzo mutuo. La adecuada y realista participación de los padres debe contemplarse en este "diseño ecológico" del plantel (véanse consideraciones similares en Hopkins y Levin, 2000).

\subsection{Democratizar la vida infantil en la institución escolar}

Escuelas autoritarias o, por el contrario, de laissez-faire no educan a los niños y niñas para vivir en democracia ni les permiten ir tomando más en sus manos su propio aprendizaje: los alumnos marchan a ciegas, resolviendo el día a día de pequeñas tareas impuestas, o se desenvuelven en el desorden y el errático devenir de la escuela permisiva. El poco poder limita y causa desafección; la desorganización y la anomia atomizan y dispersan. La escuela democrática potencia la metacognición, educa el civismo y estimula la participación activa del aprendiz en su 
propio aprendizaje, facilitando la corrección de fallas y reafirmando logros. En "Los Tres Osos" el esfuerzo por la organización y la disciplina democráticas estaba presente día a día.

\subsection{Combinar diversos tipos de activi- dades, de diversa longitud, complejidad y hetero-estructuración, incluidas las actividades de investigación estudiantil}

Creemos necesario abrirle importantes espacios a los proyectos estudiantiles de investigación dentro de la escuela, acompañándolos y complementándolos con labores más cortas y estructuradas "desde afuera" (como demostraciones, ejercicios reflexivos de papel y lápiz, o pequeñas experiencias de laboratorio), junto a actividades de índole exploratoria. Los proyectos plantean posibilidades de aprendizaje imposibles de lograr con iniciativas más cerradas: el auténtico planteo de inquietudes sentidas, la planificación propia, la organización en equipos de trabajo, el seguimiento de la propia labor, el desarrollo de diversos procedimientos investigativos, la comunicación de lo investigado. Esta estrategia didáctica encierra así importantes logros cognitivos y afectivos.

$\mathrm{Su}$ acompañamiento cuidadoso con actividades más breves y más delimitadas permite atender a ciertos objetivos considerados relevantes por la institución escolar. A la vez que la presencia de otras actividades más abiertas y difusas que los proyectos va abriendo nuevas perspectivas a los alumnos. La escuela estudiada no ha logrado todavía este balance, pues su esfuerzo por el desarrollo de proyectos se ha visto frustrado dada las dificultades de esta labor y las orientaciones demasiado inflexibles y poco prácticas con que los educadores del plantel han tenido contacto.

\subsection{Construir la base material para un buen trabajo}

En el mejoramiento de la escuela, especialmente de la escuela pública, no todo es cuestión de dinero, pero sí hay una parte que tiene que ver con él y que se refiere a la construcción de una base material de trabajo que permita en verdad otra forma de estar y de aprender en la escuela. Aulas de treinta y ocho alumnos, ausencia de biblioteca, el texto escolar como único recurso, las dificultades económicas para visitas y excursiones, los estrechos patios, los pupitres en fila, todo ello conforma un ambiente pobre y monótono, donde el trabajo docente de calidad se hace inviable de manera sostenida: son ambientes que conducen a la rutina simple y escasamente formativa. No quiere decir que al día siguiente de dotar bien una escuela florecerán los proyectos y las actividades creativas, sino que al tener la base puede entonces empezar a construirse el edificio del aprendizaje escolar de calidad. Países más pobres afrontan aquí un gran reto, que ha de responderse priorizando la inversión educativa y diseñando a la vez respuestas ingeniosas a las inevitables menores disponibilidades en el presupuesto por alumno. Confiar exclusivamente en rediseños a partir de la misma escasa inversión, que no alcanza un umbral crítico, resulta inviable. "Los Tres Osos" nos enseña cómo, contando con un apoyo financiero adecuado, si bien no entre los más altos del mundo, es posible ir desarrollando unos ambientes y una dotación favorecedores de la formación de los niños y niñas.

\section{Referencias}

Alberti, A. (1977). Introducción. En Ciari, B. Modos de enseñar, pp. 5-19. Barcelona: Avance. (I modi dell' insegnare. Editori Riuniti. Ro$\mathrm{ma})$.

Blumenfeld, P. C.; Marx, R. W.; Patrick, H.; Krajcik, J. y Soloway, E. (1997). Capítulo 4: Teaching for Understanding. En Biddle, B. J.; Good, T. L. y Goodson, I. F., eds., International Handbook of Teachers and Teaching, pp. 819878. Dordrecht / Boston / Londres: Kluwer.

Bransford, J. D.; Brown, A. L. y Cocking, R., eds. (2000). How people learn. Brain, mind, experience, and school. 3a. Reimpresión, abril 2001. 
Washington, D. C.: National Academy of Sciences.

Carr, W. y Kemmis, S. (1988). Teoría crítica de la enseñanza. Barcelona: Martínez-Roca.

Claxton, G. (1994). Educar mentes curiosas. El reto de la ciencia en la escuela. Col. Aprendizaje. Madrid: Visor. (Educating the Inquiring Mind. 1991).

Claxton, G. (2001). Aprender. El reto del aprendizaje continuo. Barcelona: Paidós. (Wise Up. Bloomsbury Publishing, R. U., 1999).

Damasio, A. R. (1994). Descartes' Error. Nueva York: Grosset-Putnam. (Hay traducción al castellano).

Eisner, E. W. (1998). El ojo ilustrado. Indagación cualitativa y mejora de la práctica educativa. Barcelona / Buenos Aires / México: Paidós. (The enlightened eye. Qualitative inquiry and the enhancement of educational practice. Prentice Hall, 1990)

Erickson, F. (1998). Qualitative Research Methods for Science Education. En Fraser, B. J. y Tobin, K. G., eds., International Handbook of Science Education, pp. 1155-1173. Dordrecht / Boston / Londres: Kluwer.

Gallas, K. (1995). Talking their way into science. Hearing children's questions and theories, responding with curricula. Nueva York: Teachers College.

Goodman, J. (2001). La educación democrática en la escuela. Sevilla: Publicaciones M.C.E.P.

Guba, E. G. (1983). Criterios de credibilidad en la investigación naturalista. En Gimeno Sacristán, J. y Pérez Gómez, A. I., La enseñanza: su teoría y su práctica, pp. 148-165. Madrid: Akal.

Hatano, G. e Inagaki, K. (1997). Qualitative changes in intuitive biology. European Journal of Psychology of Education. XII (2): 111-130.

Hopkins, D. y Levin, B. (2000). Educational Reform and School Improvement. NIRA Review. 7 (3): 21-26. Disponible: http://www.nira.go.jp/publ/review/2000summer/h opkins.pdf Y también accesible a través de la Biblioteca Virtual de RINACE: http://www.uam.es/otros Consultado el 05-122003.

Koch, J. y Burghardt, M. D. (2002). Design Technology in the Elementary School -A Study of Teacher Action Research. Journal of Technol- ogy Education. 13 (2). Disponible: http://scholar.lib.vt.edu/journals/JTE/v13n2/koch. html Consultado el 02-12-2003.

Lacueva, A. (2000a). Ciencia y Tecnología en la escuela. Caracas / Madrid: Laboratorio Educativo / Popular.

Lacueva, A. (2000b). Investigar para transformar: el paradigma crítico en la investigación educativa. Revista de Pedagogía. XXI (61): 145-167.

Lakoff, G. (1987). Women, Fire and Dangerous Things. What categories reveal about the mind. Chicago: The University of Chicago Press.

Lakoff, G. y Johnson, M. (1999). Philosophy in the flesh. The embodied mind and its challenge to western thought. Nueva York: Basic.

Lawson, A. E. (1994). Uso de los ciclos de aprendizaje para la enseñanza de destrezas de razonamiento científico y de sistemas conceptuales. Enseñanza de las Ciencias. 12 (2): 165-187.

Manning, M.; Manning, G. y Long, R. (2000) Inmersión temática. El currículo basado en la indagación para los primeros años y años intermedios de la escuela elemental. Barcelona: Gedisa. (Theme Immersion: Inquiry-Based Curriculum in Elementary and Middle Schools. Portsmouth, NH: Heinemann, 1994).

Poddiákov, N. (1987). Sobre el problema del desarrollo del pensamiento en los preescolares. En VV.AA., La psicología evolutiva y pedagógica en la URSS. Antología, pp. 168-172. Moscú: Progreso. (Versión completa original: El pensamiento del preescolar. Editorial Pedagógica. Moscú, 1977).

Ramos, J. (1999). Preguntar, debatir, indagar, compartir, cuestionar, reconsiderar, concluir... para aprender. Investigación en la Escuela. 38: 45-64.

Stake, R. E. (1998). Investigación con estudio de casos. Madrid: Morata. (The Art of Case-Study Research. Sage. Estados Unidos / Londres / Nueva Delhi, 1995).

Stenhouse, L. (1991). Métodos de estudio de casos. En Husén, T. y Postlethwaite, T. N., eds., Enciclopedia Internacional de la Educación. Volumen 7, pp. 3911-3916. Madrid: M.E.C. I Vicens Vives. (Orig.: International Encyclopedia of Education. Research and Studies. Pergamon. Oxford, 1987). 
ANEXO

\section{Programación de la unidad didáctica Los Peces}

\section{Objetivos}

- Reconocer y describir el nacimiento

- Reconocer la forma típica del pez

- Observar y comparar peces de especies diferentes

- Desarrollar actitudes de curiosidad y de interés por conocer el hábitat de los peces

- Desarrollar actitudes de investigación e indagación

- Desarrollar una expresión correcta, utilizando el vocabulario adecuado

- Utilizar correctamente la lupa

- Tener curiosidad hacia los peces

\section{Contenidos Conceptuales}

- Rasgos fundamentales del ciclo vital (nacer, crecer, reproducirse y morir)

- Principal característica de los vertebrados

- Crecimiento y desarrollo de los peces

- El movimiento y el desplazamiento

- Iniciación al conocimiento de la pecera

- Factores ambientales y adaptación del pez a su ambiente

\section{Contenidos Procedimentales}

- Observación directa e indirecta de las características externas del pez

- Observación directa de los hábitats de los peces

- Descripción oral y gráfica de los nuevos conocimientos

- Formulación de hipótesis

- Consulta de libros y otros materiales

- Recogida de datos

-Utilización de la lupa

- Clasificación de los animales que viven en el mar

- Memorización del vocabulario nuevo

- Montaje de la pecera

\section{Contenidos Actitudinales}

- Colaboración en las actividades del grupo

- Espíritu de observación

- Deseo de saber

- Responsabilidad en el uso de materiales e instrumentos

- Interés por la observación

-Esfuerzo en la expresión verbal

- Interés por la buena presentación de los trabajos

- Respeto por los seres vivos 


\section{ABOUT THE AUTHORS / SOBRE LOS AUTORES}

Aurora Lacueva (lacter@cantv.net) es profesora en la Escuela de Educación de la Universidad Central de Venezuela. Trabaja en las áreas de enseñanza de las ciencias naturales y pedagogía general. Ha publicado recientemente los libros Ciencia y Tecnología en la Escuela y Más de 400 ideas para actividades y proyectos estudiantiles de investigación. Dirección de contacto: Apartado Postal No 51510, Sabana Grande, Caracas 1050-A, Venezuela. Tlf. y Fax: ++ (58-212) 605.3000.

Francisco Imbernón Muñoz (fimbernon@ub.edu) es catedrático de Didáctica y Organización Escolar. Su especialización es la formación del profesorado. Ha realizado tareas en formación inicial y en la formación permanente del profesorado de todos los niveles educativos, desde la primaria hasta la Universidad, y en la formación de profesionales y formadores de diversos sectores. Ha recibido varios premios por su labor y ha publicado diversos libros. Dirección de contacto: Departamento de Didáctica y Organización Educativa de la Universidad de Barcelona. Paseo del Valle Hebrón, 171, edifico de Levante, $2^{\circ}$ piso. 08035, Barcelona (España).

Rosa Llobera (rllobera@,d5.ub.es) es catedrática de Didáctica de las Ciencias Experimentales. Actualmente trabaja en deteccion de ideas previas y esquemas de razonamiento y en el diseño de posibles estrategias, principalmente de forma experimental, para la enseñanza-aprendizaje de conceptos químicos en alumnos de Secundaria y Primaria, así como en la elaboracion de unidades didácticas. Dirección de contacto: Departamento de Didáctica de las Ciencias Experimentales y la Matemática, Universidad de Barcelona. Passeig de la Vall d' Hebron, 171. Edificio de Levante, 1er. Piso. 08035 Barcelona (España). 


\title{
ARTICLE RECORD / FICHA DEL ARTÍCULO
}

\begin{tabular}{|c|c|}
\hline $\begin{array}{l}\text { Reference / } \\
\text { Referencia }\end{array}$ & $\begin{array}{l}\text { Lacueva, Aurora, Imbernón, Francisco y Llobera, Rosa (2004). Los peces: una unidad didáctica en una escuela “dife- } \\
\text { rente". Revista ELectrónica de Investigación y EValuación Educativa, v. 10, n. 2. } \\
\text { http://www.uv.es/RELIEVE/v10n2/RELIEVEv10n2 3.htmConsultado en (poner fecha). }\end{array}$ \\
\hline Title / Título & Los peces: una unidad didáctica en una escuela "diferente”. [Fishes: a didactical unit in an uncommon school] \\
\hline $\begin{array}{l}\text { Authors / } \\
\text { Autores }\end{array}$ & Aurora Lacueva, Francisco Imbernón y Rosa Llobera \\
\hline $\begin{array}{l}\text { Review / } \\
\text { Revista }\end{array}$ & Revista ELectrónica de Investigación y EValuación Educativa (RELIEVE), v. 10, n. 2 \\
\hline ISSN & $1134-4032$ \\
\hline $\begin{array}{l}\text { Publication } \\
\text { date / } \\
\text { Fecha de } \\
\text { publicación }\end{array}$ & 2004 (Reception Date: 2003 Dec 21; Approval Date: 2004 June 30; Publication Date: 2004 July 30) \\
\hline $\begin{array}{l}\text { Abstract / } \\
\text { Resumen }\end{array}$ & $\begin{array}{l}\text { In this case study we describe and interpret a didactical experience centered on the theme "Fishes" and } \\
\text { developed in a first-grade classroom of an innovative school. We systematically recorded the experience, } \\
\text { collected documents, and interviewed the principal, the teacher and the students. Seven categories were } \\
\text { used for the interpretation of data: learning connected to the real world, availability of sufficient resources, } \\
\text { excessive narrowness of the theme, openness vs. structure in the didactical work, children as protagonists, } \\
\text { a rich school life beyond the classroom, and the multi-faceted relation between school and home. The arti- } \\
\text { cle outlines and discusses children's learning achievements. } \\
\text { En este estudio de casos se describe y se interpreta reflexivamente una experiencia didáctica centrada en } \\
\text { el tema "Los Peces", y desarrollada en un primer grado deeducación primaria dentro de una escuela inno- } \\
\text { vadora. Se llevó un registro sistemático de lo sucedido, se recopilaron documentos y se realizaron entrevis- } \\
\text { tas. Para la interpretación de lo observado, se trabajó con siete categorías que intentan destacar importantes } \\
\text { características de la experiencia:un aprendizaje vinculado al mundo exterior, disponibilidad de suficientes } \\
\text { recursos, la excesiva delimitación del tema en estudio, aperturafrente a estructura en el trabajo didáctico, } \\
\text { niños y niñas protagonistas, una escuela de rica vida más allá del aula, y la multifacética relación escuela- } \\
\text { hogar. El artículo aporta consideraciones acerca de los aprendizajes logrados por los estudiantes }\end{array}$ \\
\hline $\begin{array}{l}\text { Keywords } \\
\text { Descriptores }\end{array}$ & $\begin{array}{l}\text { Educative innovation, science education, democratic education, didactics, elementary school education. } \\
\text { Innovación educativa, enseñanza de las ciencias naturales, educación democrática, didáctica, educación } \\
\text { primaria }\end{array}$ \\
\hline $\begin{array}{l}\text { Institution / } \\
\text { Institución }\end{array}$ & Universidad Central de Venezuela y Universidad de Barcelona (España) \\
\hline $\begin{array}{l}\text { Publication } \\
\text { site / } \\
\text { Dirección }\end{array}$ & http://www.uv.es/RELIEVE \\
\hline $\begin{array}{l}\text { Language / } \\
\text { Idioma }\end{array}$ & Español (Title, abstract and keywords in english ) \\
\hline
\end{tabular}

\section{Revista ELectrónica de Investigación y EValuación Educativa (RELIEVE)}

\author{
[ ISSN: 1134-4032 ]
}

(C) Copyright, RELIEVE. Reproduction and distribution of this articles it is authorized if the content is no modified and their origin is indicated (RELIEVE Journal, volume, number and electronic address of the document).

(C) Copyright, RELIEVE. Se autoriza la reproducción y distribución de este artículo siempre que no se modifique el contenido y se indique su origen (RELIEVE, volumen, número y dirección electrónica del documento). 